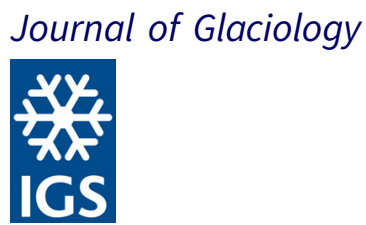

\section{Article}

Cite this article: Blau MT, Turton JV, Sauter T, Mölg T (2021). Surface mass balance and energy balance of the $79 \mathrm{~N}$ Glacier (Nioghalvfjerdsfjorden, NE Greenland) modeled by linking COSIPY and Polar WRF. Journal of Glaciology 67(266), 1093-1107. https://doi.org/10.1017/jog.2021.56

Received: 23 September 2020

Revised: 2 May 2021

Accepted: 4 May 2021

First published online: 7 June 2021

\section{Keywords:}

Glacier mass balance; glacier modeling; ice/atmosphere interactions; mass-balance reconstruction; surface mass budget

\section{Author for correspondence:}

M. T. Blau, E-mail: manuel.blau@pusan.ac.kr

\title{
Surface mass balance and energy balance of the 79N Glacier (Nioghalvfjerdsfjorden, NE Greenland) modeled by linking COSIPY and Polar WRF
}

M. T. Blau ${ }^{1,2,3}$ (D) J. V. Turton ${ }^{1}$ (D), T. Sauter ${ }^{1}$ (D) and T. Mölg${ }^{1}$ (i)

${ }^{1}$ Climate System Research Group, Institute for Geography, Friedrich-Alexander University, Erlangen, Germany; ${ }^{2}$ Center for Climate Physics, Institute for Basic Science, Busan 46241, South Korea and ${ }^{3}$ Department of Climate System, Pusan National University, Busan 46241, South Korea

\section{Abstract}

To get a better overview of atmosphere-driven mass changes at the $79 \mathrm{~N}$ Glacier (Nioghalvfjerdsfjorden Glacier), the largest outlet glacier of the northeast Greenland ice stream, the surface mass balance (SMB) is modeled by linking the COupled Snowpack and Ice surface energy and mass-balance model in PYthon (COSIPY) with the output of a regional atmospheric model (Polar WRF) for the years 2014-2018. After a manual model optimization, the model produces reliable results when compared to observations in the region and to values from the literature. High spatial resolution $(1 \mathrm{~km})$ simulations reveal strong interannual variability of the SMB. Stronger surface melting increased the ablation and runoff in years with high mass loss (2016 and 2017) whereas in other years (2015 and 2018) melting and refreezing inside the snowpack dominated the mass balance $(\mathrm{MB})$. A cooler regional climate with higher snowfall-driven accumulation, higher albedo and reduced surface melt in the ablation period of 2018 resulted in a positive SMB in 2018, however, the annual total MB remained negative. The results suggest a promising new dataset for gaining more insights into mass-balance processes and their contribution to the acceleration of glacier retreat in northeast Greenland.

\section{Introduction}

The northeast Greenland ice stream (NEGIS) covers an area of $\sim 200000 \mathrm{~km}^{2}$ of the Greenland ice sheet (GrIS) and drains through three marine-terminating outlet glaciers (Fig. 1). Together, those drain $\sim 12 \%$ of the GrIS (Fig. 1a; Mayer and others, 2018). The largest of those is called the Nioghalvfjerdsfjorden Glacier, also referred to in English (including throughout this paper) as $79 \mathrm{~N}$ Glacier. Approximately $8.4 \%$ of the GrIS drains through the $79 \mathrm{~N}$ Glacier to the ocean (Huybrechts and others, 1999). With a drainage basin of $\sim 120000 \mathrm{~km}^{2}$, the $79 \mathrm{~N}$ Glacier has the largest outlet of the GrIS and is the Arctic's largest remaining ice shelf (Seroussi and others, 2011).

The floating tongue of the $79 \mathrm{~N}$ Glacier directly connects the GrIS to the Atlantic Ocean (Schaffer and others, 2017). It is $\sim 8 \mathrm{~km}$ wide at the grounding line and extends $\sim 80 \mathrm{~km}$ long into the Nioghalvfjerds fjord. At the terminus, the glacier tongue widens to $\sim 30 \mathrm{~km}$ (Thomsen and others, 1997; Reeh and others, 1999; Reeh and others, 2000). The glacier thickness increases from $\sim 50 \mathrm{~m}$ at the glacier margins to $250-600 \mathrm{~m}$ at the grounding line (Huybrechts and others, 1999; Reeh and others, 2000; Schaffer and others, 2016). The inland extent of the glacier is difficult to outline, as it joins with Zachariae Isstrøm (ZI) and Storstrømmen Glaciers to become the NEGIS. However, the glacier outlines can be approximately determined by the high ice velocity compared to the surrounding ice sheet (Fig. 1b; Krieger and others, 2020).

The $79 \mathrm{~N}$ Glacier was assumed to be stable until the early 21 st century (Joughin and others, 2010). However, recent observations revealed increasing surface velocities and glacier thinning (Khan and others, 2014). Dynamical mass loss through numerous small calving events led to an area reduction of $\sim 65.4 \mathrm{~km}^{2}$ between 1999 and 2013 (Jensen and others, 2016). This is $\sim 4 \%$ of the total area of the floating portion of the glacier. Andersen and others (2019) reported an average annual area change of $\sim-2.7 \mathrm{~km}^{2} \mathrm{a}^{-1}$ from 1999 to 2018 . Additional retreat is now likely following the $100 \mathrm{~km}^{2}$ calving of Spaltegletsjer (a tributary of 79N) in 2019 and 2020 (personal communication from Jason Box, 4 September 2020). The glacier is exposed to both changes in atmosphere and ocean circulation. The trapping of relatively warm Atlantic water under the glacier tongue by a sill leads to a basal melt rate of $10.4 \pm 3.1 \mathrm{~m} \mathrm{a}^{-1}$ (Schaffer and others, 2020). Enhanced basal melting in particular years is likely driven by atmospheric processes which drive additional warm water into the cavity of beneath the floating tongue (Münchow and others, 2020). Additional variability in the mass balance (MB) comes from the surface mass balance (SMB) changes (Mouginot and others, 2019). The $79 \mathrm{~N}$ Glacier region has experienced $3{ }^{\circ} \mathrm{C}$ warming of the average air-temperature over the last 40 years (Turton and others, 2019a), and persistent supraglacial melt lakes now feature on both the floating tongue and grounded part of the glacier (Leeson and others, 2015; Hochreuther and others, 2021). The equilibrium line altitude (ELA) is likely to increase in altitude within the 21st century (Leeson and others, 2015; Noël and others, 2019). 
a Ice Velocity GrIS $14 / 12 / 2019-07 / 01 / 2020$
Site Map of $79 \mathrm{~N}$ including AWS and Stake Observation Location
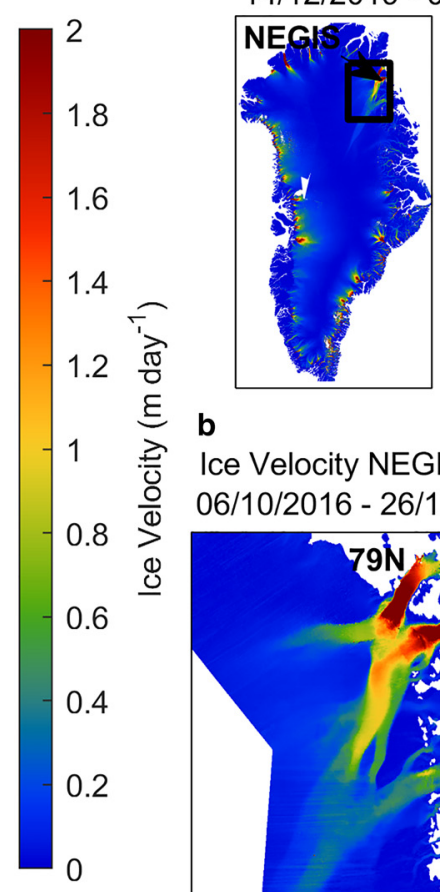

b

Ice Velocity NEGIS 06/10/2016 - 26/10/2016
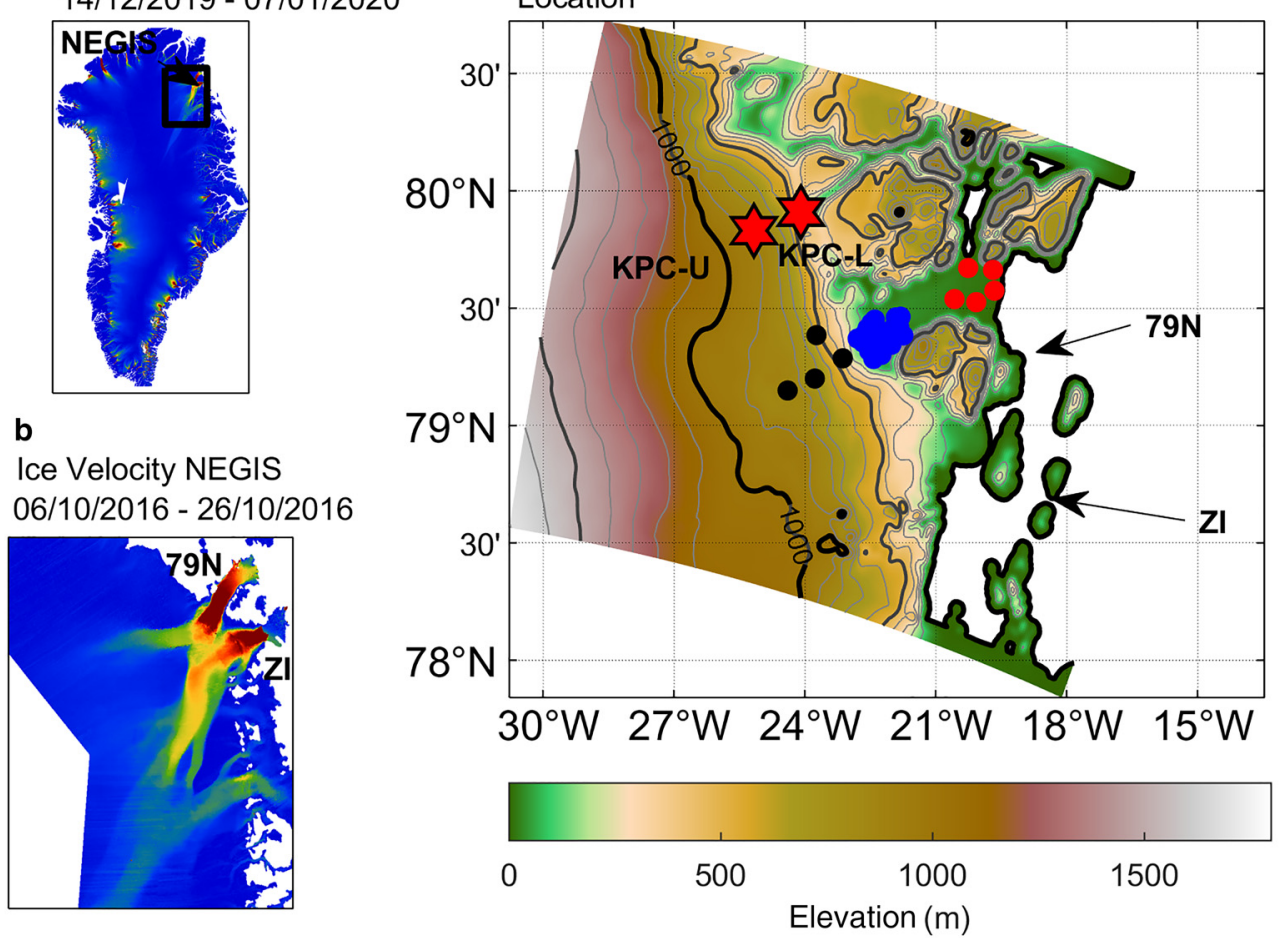

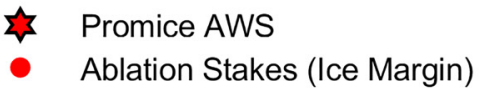

- Ablation Stakes (Grounding Line)

- Ablation Stakes (High Altitude)

Fig. 1. Ice velocity of the GrIS from 14 December 2019 to 7 January 2020 (a) and the NEGIS from 6 October to 26 October 2016 (b) (Solgaard and Kusk, 2019 ). Site map of the $79 \mathrm{~N}$ and the lower drainage basin of the NEGIS (c). The map in (c) shows the elevation taken from the PWRF output and presents the modeled domain. The isolines indicate $100 \mathrm{~m}$ (gray) and $1000 \mathrm{~m}$ (black) altitude steps. Stars show locations of the AWSs from PROMICE (Fausto and van As, 2019) and points show the location of surface ablation stakes (Zeising and others, 2020).

Due to the remoteness of the 79N Glacier there are only a couple of SMB measurements and climate observations from automatic weather stations (AWSs) available (Fig. 1). Therefore, to estimate SMB of the glacier, models are valid tools. Several studies have been conducted recently concerning SMB of Greenland. Those attempts use diverse models such as the regional atmospheric climate model RACMO2 (e.g. Ettema and others, 2009; Noël and others, 2018; Mouginot and others, 2019), the Modèle Atmosphérique Régional (MAR) (e.g. Fettweis, 2007), a degreeday model (e.g. Mayer and others, 2018) or other climate-SMB models (e.g. The IMBIE Team, 2020) to detect mass changes, and flowline models to simulate ice velocity and glacier outlines (Krieger and others, 2020). Others achieved their results concerning the $\mathrm{MB}$ or ice thickness change with data from satellite missions or from other air-borne surveys (e.g. Seroussi and others, 2011; Khan and others, 2014). However, common focus was set on mass changes of the entire GrIS on a rather coarse grid and NEGIS was treated as a part of GrIS. This leads to an underrepresentation of the large spatial and temporal variability of SMB in the $79 \mathrm{~N}$ region which cannot be captured in a coarse grid in its full entity (Mayer and others, 2018; Noël and others, 2018; Turton and others, 2019a).

Prior to the current study, high-resolution SMB modeling down to a spatial resolution of $2.5 \mathrm{~km}$ was only available until 1997 (Huybrechts and others, 1999). Therefore, recent intensive melt events or the effects of warm air advection during winter (Turton and others, 2019a), are not incorporated or poorly resolved by coarser-resolution SMB models which simulate the whole of Greenland. Other unsolved questions include the ratio of meltwater that runs off into the ocean, refreezes or is stored as liquid water in ice pores or meltwater ponds. Previously, Turton and others (2020) applied the Polar version of the Weather Research and Forecasting Model (PWRF) with $1 \mathrm{~km}$ spatial resolution on the domain shown in Figure 1c, to investigate the dominant atmospheric processes and climatology of the region. The current study attempts to link the PWRF atmospheric output with a recently developed SMB model called the COupled Snowpack and Ice surface energy and mass-balance model in PYthon (COSIPY) (Sauter and others, 2020). COSIPY was previously tested for Himalayan glaciers (Sauter and others, 2020) with observations from AWS as atmospheric input. However, as yet, COSIPY has not been tested in a one-way, offline coupled setting, using high-resolution 4-D model output from an atmospheric model as input. Here, we use the PWRF data as input and explore which parameter settings for COSIPY are appropriate for our region of interest. The goals of this study are twofold. First, we evaluate the accuracy of COSIPY in its ability to simulate the SMB when linked with PWRF. Second, once we have confidence in the model for this region, we use it to produce a highresolution $(1 \times 1 \mathrm{~km})$ dataset of SMB for the $79 \mathrm{~N}$ Glacier. This study will provide a basis for studying the acceleration of mass loss in the $79 \mathrm{~N}$ region further and to investigate the relationship between specific atmospheric processes and SMB. The modeled data (available from www.doi.org/10.5281/zenodo.4434259) can provide the foundations of a deeper understanding of the processes effecting the $\mathrm{MB}$ of this remote region.

The paper continues with a description of the COSIPY model and the observations used to manually optimize and evaluate the model (Section 2). The results are split into different sections, beginning with model optimization and evaluation (Section 3.1) 
Table 1. List of input data from PWRF, AWS and stake observations including the time span of data usage and used variables

\begin{tabular}{|c|c|c|c|c|c|c|c|}
\hline Data & Latitude ${ }^{\circ} \mathrm{N}$ & Longitude ${ }^{\circ} \mathrm{W}$ & Altitude $\mathrm{m}$ & Start & End & Usage & Reference \\
\hline PWRF $^{\mathrm{a}}$ & - & - & - & $14 / 07 / 2014$ & $31 / 12 / 2018$ & Input & Turton and others (2019b) \\
\hline$K P C-L^{b}$ & 79.90 & 24.08 & 255.6 & $01 / 01 / 2015$ & $31 / 12 / 2015$ & Optimization & Fausto and van As (2019) \\
\hline$K P C-U^{b}$ & 79.83 & 25.16 & 907.2 & $01 / 01 / 2015$ & $31 / 12 / 2015$ & Optimization & \\
\hline$K P C-L^{b}$ & 79.90 & 24.08 & 255.6 & $01 / 08 / 2014$ & $31 / 12 / 2018$ & Evaluation & \\
\hline$K P C-U^{b}$ & 79.83 & 25.16 & 907.2 & $01 / 08 / 2014$ & $31 / 12 / 2018$ & Evaluation & \\
\hline Ablation stakes ${ }^{c}$ & - & - & - & $07 / 2017$ & $07 / 2018$ & Evaluation & Zeising and others (2020) \\
\hline
\end{tabular}

${ }^{a} 2 \mathrm{~m}$ air-temperature, $2 \mathrm{~m}$ air-pressure, incoming shortwave radiation, incoming longwave radiation, snowfall, total precipitation, wind-speed (horizontal wind vectors), initial information (skin temperature, water content, snow height, total height).

${ }^{\text {b}}$ Surface temperature, outgoing longwave radiation, shortwave albedo, snow height.

${ }^{\mathrm{c}}$ Surface height change.

and followed by presentation and discussion of the surface mass and energy balance for the 79N Glacier from 2014 to 2018 (Section 3.2). The paper concludes in Section 4.

\section{Data and methods}

The concept of driving a process-based MB model with highresolution atmospheric model output over multiple years was successful for mountain glaciers (e.g. Mölg and others, 2014), and hence it seems a promising approach for the current study. Furthermore, due to the sparse atmospheric observations in the region and the large area of $79 \mathrm{~N}$, using high-resolution input from an atmospheric model, as opposed to localized in situ observations, should yield more accurate results with regard to spatial variability. Several in situ observations of SMB, radiation and near-surface meteorological data are used for model optimization and evaluation of the results. Table 1 lists all data used in this study.

\subsection{Study site}

The regional climate is dominated by the characteristic annual cycle of the high-Arctic region, with the polar night (October to April), when no sunlight reaches the area, and the polar day (April to September). Two AWSs from the PROMICE network are located on the Kronprins Christian Land, just north of the $79 \mathrm{~N}$ Glacier. A lower station is located in the ablation zone (KPC-L; where L stands for lower) and an upper station is near the equilibrium line (KPC-U; where $\mathrm{U}$ stands for upper; Fig. 1; Fausto and van As, 2019). Cold conditions with annual mean temperatures (2009-18) of $-13.4 \pm 1.5^{\circ} \mathrm{C}$ (KPC-L) and $-16.6 \pm$ $0.5^{\circ} \mathrm{C}$ (KPC-U) characterize the local climate (Turton and others, 2019a). The average summer temperature does not exceed the melting point at KPC-U, although daily maximum values can reach up to $4^{\circ} \mathrm{C}$ (Turton and others, 2019a). Katabatic winds dominate the wind conditions. The strong temperature variability during winter is due to a combination of regional scale meteorological conditions, such as warm air advection from passing storms (Turton and others, 2019a), and large-scale variability associated with teleconnections (Lim and others, 2016; Hahn and others, 2018).

\subsection{Input data from Polar WRF}

Data for the initialization of COSIPY comes from a highresolution $(1 \mathrm{~km})$ Polar WRF (PWRF) output. PWRF is a polaroptimized version of the WRF model (Hines and others, 2008). The atmospheric modeling was conducted and evaluated by Turton and others (2020) using version v3.9.1.1 of PWRF. The output is available online (https://osf.io/53e6z/; last accessed on 9 May 2020). The data are available at hourly resolution for the domain shown in Figure 1c. Model outputs for this study from July 2014 to December 2018 are used. July 2014 is treated as a spin-up period, to ensure a minimum snow height (or no fresh snow as observed by a monthly average albedo of 0.47 at KPC-L, representing bare ice; Ryan and others, 2019) at the glacier surface starting August 2014 (Section 2.4). The experiment setup and parameterization for the PWRF modeling are described in Turton and others (2020).

\subsection{Observations}

\subsubsection{PROMICE weather stations}

COSIPY is optimized with observations from two AWSs just north of $79 \mathrm{~N}$ Glacier at two altitudes at the Kronprins Christian Land (Fig. 1c). KPC-L, in the ablation zone has an elevation of $255.6 \mathrm{~m}$ a.s.l., KPC-U is located near the equilibrium line at an elevation of $907.2 \mathrm{~m}$ a.s.l. (Table 1). The data are corrected (e.g. tilt-correction) and quality controlled according to the procedure by van As (2011) and are available online at the PROMICE homepage (http://www.promice.org/PromiceDataPortal/; last accessed on 10 May 2020; Fausto and van As, 2019). However, measurement errors cannot be completely excluded (Turton and others, 2019a). Data from these locations were previously used to evaluate the PWRF atmospheric and radiation variables (Turton and others, 2020). To handle the noise in the snow height data, daily changes are calculated as difference in 'midnight' values defined as mean of all hourly values between 22:00 and 02:00 local time (LT), following Mölg and others (2020). For COSIPY optimization the PROMICE data from January to December 2015 are used, as there are no missing values for all required input variables; the evaluation of COSIPY-WRF spans from August 2014 to December 2018 (Table 1).

\subsubsection{Stake observations}

In situ data from a field campaign conducted by the Alfred Wegener Institute (AWI) as a contribution to the Greenland Ice Sheet Ocean Interaction project (https://groce.de/en/; last accessed on 10 May 2020) are also used for independent evaluation of COSIPY-WRF. The observations are previously unpublished surface ablation estimates using ablation stakes on the $79 \mathrm{~N}$ Glacier (Fig. 1c). Data are available for download from https://doi.pangaea.de/10.1594/PANGAEA.922131 (Zeising and others, 2020). The ablation stakes were installed in July 2017 and observations of snow height were taken in July 2018, which give the height change at the stake sites for 1 year. At each site, four stakes were installed, to prevent data loss in case of a failure of one stake, and to provide uncertainties in surface height change estimates.

The elevation and location of the stakes was recorded with a GPS device which has an elevation accuracy of $\sim 10 \mathrm{~m}$. The elevation of the stakes on the floating tongue is also subjected to an 
Table 2. Parameterization and parameters selection for the COSIPY-WRF run

\begin{tabular}{|c|c|c|}
\hline Constant/module & Parameter/parameterization & References \\
\hline Stability correction & 'Ri' & Braithwaite (1995) \\
\hline Albedo method & 'Oerlemans98' & Oerlemans and Knap (1998) \\
\hline Densification method & 'Boone' & Essery and others (2013) \\
\hline Radiation penetration method & 'Bintanja95' & Bintanja and van den Broeke (1995) \\
\hline Roughness method & 'Moelg12' & Mölg and others $(2009,2012)$ \\
\hline Initial bottom temperature & $258.7 \mathrm{~K}$ & Cullen and others (2014) \\
\hline Albedo fresh snow & 0.87 & van de Wal and Oerlemans (1994); Bøggild and others (2010) \\
\hline Albedo firn & 0.78 & \\
\hline Albedo ice & 0.525 & \\
\hline Albedo time scaling factor & $2 d$ & \\
\hline Albedo depth scaling factor & $12.5 \mathrm{~cm}$ & \\
\hline Roughness length fresh snow & $0.5 \mathrm{~mm}$ & $\begin{array}{l}\text { Smeets and van den Broeke (2008); Cullen and others (2014); Fausto and } \\
\text { others (2016) }\end{array}$ \\
\hline Roughness length firn & $1.7 \mathrm{~mm}$ & \\
\hline Roughness length ice & $3.5 \mathrm{~mm}$ & \\
\hline Surface emissivity & 0.99 & Noël and others (2018) \\
\hline Density threshold to firn & $400 \mathrm{~kg} \mathrm{~m}^{-3}$ & Cullen and others (2014) \\
\hline Density threshold to ice & $800 \mathrm{~kg} \mathrm{~m}^{-3}$ & Herron and Langway (1980) \\
\hline
\end{tabular}

References are provided where value/value ranges have been used from previous studies. Each parameter was tested according to the options and ranges indicated by Tables 5 and 6 in Appendix B.

additional error of $3 \mathrm{~m}$ due to the tidal movement. We used the coordinates of the GPS to select the closest gridpoint in the COSIPY-WRF output for comparison. The uncertainties in stake location do not translate to an uncertainty of the surface height change, but to the elevation of the stake observations (personal communication from Zeising, 5 February 2020). The measured GPS locations are listed in Table 4 in Appendix A.

\section{4. $\operatorname{COSIPY}$}

\subsubsection{Structure and optimization}

COSIPY is available online in its current release as an open-source software, we use v1.1 for this study (https:/github.com/cryotools/ cosipy; last accessed on 9 May 2020; Sauter and Arndt, 2020). It is a physical surface energy and MB model that assumes full mass conservation in the snowpack. Therefore, it calculates the different mass fluxes by distinguishing between internal mass balance (IMB) and SMB. The sum of IMB and SMB is the total MB (TMB). In COSIPY, IMB summarizes the subsurface melt and the refreezing of meltwater, and SMB summarizes all MB processes at the surface including surface melt, snowfall, sublimation and deposition. Excess meltwater can be held in the snow layers as liquid water content. If one layer is saturated, meltwater drains in the next layer below (tipping bucket approach) or runs off when it reaches the surface below the lowest model layer (Sauter and others, 2020). By doing so, the model divides the snow and ice pack into several user-defined numbers of layers in the vertical (Sauter and others, 2020).

The ablation component relies on the surface energy balance (SEB). An energy surplus at the surface can cause melting (if the surface temperatures reach $0^{\circ} \mathrm{C}$ ). A negative $\mathrm{SEB}$, on the other hand, causes cooling of the surface layers. Sublimation or deposition also occurs depending on the surface-air water vapor pressure gradient between the surface and the surface layer. In COSIPY, SMB is computed as the difference of the total accumulation at the surface (snowfall accumulation and deposition) and the total ablation at the surface (surface melt and sublimation). Penetrating energy into the snowpack triggers ablation processes in the snowpack. Here, ablation occurs due to internal melting if temperatures reach $0^{\circ} \mathrm{C}$. Melt water from surface and subsurface melt can penetrate deeper snow layers and refreeze there too or is held in pores as liquid water content. Excess meltwater contributes to the runoff and leaves the domain (Sauter and others, 2020).

Carefully chosen parameter settings are needed to produce an 'optimal' model performance of COSIPY in this Arctic setup. For this reason, and as COSIPY is a newly released SMB model, a manual trial-and-error approach is preferred over an automated Monte-Carlo approach which is used for long-term documented MB models (e.g. Mölg and others, 2012; Cullen and others, 2014). A manual testing of parameter tuning gives a better idea of the response of COSIPY results to changes in the configuration. The testing followed the value ranges in Tables 5 and 6 in Appendix $\mathrm{B}$ and the final parameter selection is presented in Table 2. Input data from the two PROMICE AWSs are used from January to December 2015 for optimization (Section 2.3.1). In a second step, the model is applied to the $79 \mathrm{~N}$ domain using the PWRF data as input.

The initial englacial vertical profiles of the state variables temperature, liquid water content and density needed for the optimization are from the observations. The top-layer and bottom-layer temperatures are the mean temperatures of December 2014 and January 2015 measured at the surface and $10 \mathrm{~m}$ depth by the PROMICE AWSs $(248.40 \pm 6.4 \mathrm{~K}$ top, and $260.46 \pm 0.6 \mathrm{~K}$ bottom for KPC-L; $244.87 \pm 7.0 \mathrm{~K}$ top, and $258.66 \pm 0.1 \mathrm{~K}$ bottom for KPC-U) (Table 2). Even though the $79 \mathrm{~N}$ Glacier is reported to be much thicker than $10 \mathrm{~m}$ (e.g. Schaffer and others, 2016), the assumption regarding the constant bottom-layer temperature is reasonable. The conductive heat flux below that depth was regarded to be negligible over the timescale examined following Cullen and others (2014).

In COSIPY, the albedo is calculated with the parameterization of Oerlemans and Knap (1998). The strong variability of ice albedo, which can range from 0.1 to 0.6 depending on the surface conditions, makes it difficult to find values for the entire $79 \mathrm{~N}$ Glacier (Bøggild and others, 2010). Manual testing and inspection of the AWS data revealed that the albedo decreases from a fresh snow albedo of 0.87 to a firn albedo of 0.78 with an aging factor of $2 \mathrm{~d}$ after the snowfall event. When there is no snow layer, the albedo drops to 0.525 (van de Wal and Oerlemans, 1994). The depth scaling factor for albedo was found to be $12.5 \mathrm{~cm}$ (Table 2). The non-reflected shortwave radiation heats the surface, penetrates the snowpack and supplies the interior with energy according to Bintanja and van den Broeke (1995). The outgoing longwave radiation is calculated after updating the surface 
Table 3. Evaluation statistics (correlation coefficient - $R$ and root mean square error - RMSE) for COSIPY-WRF evaluation against PROMICE AWSs in the optimization and the evaluation period

\begin{tabular}{|c|c|c|c|c|c|}
\hline & & \multicolumn{2}{|c|}{$\begin{array}{l}\text { COSIPY-WRF } \\
\text { optimization } \\
01 / 01 / 2015- \\
31 / 12 / 2015\end{array}$} & \multicolumn{2}{|c|}{$\begin{array}{l}\text { COSIPY-WRF evaluation } \\
01 / 08 / 2014-31 / 12 / 2018 \\
\text { including (excluding) } \\
\text { optimization period }\end{array}$} \\
\hline & & KPC-L & $\mathrm{KPC}-\mathrm{U}$ & KPC-L & KPC-U \\
\hline \multirow[t]{2}{*}{ TS } & $\mathrm{R}$ & 0.95 & 0.94 & $0.92(0.92)$ & $0.90(0.91)$ \\
\hline & RMSE (K) & 3.44 & 2.03 & $4.46(4.20)$ & $5.13(4.89)$ \\
\hline \multirow[t]{2}{*}{ LWout } & $\mathrm{R}$ & 0.95 & 0.95 & $0.92(0.93)$ & $0.91(0.92)$ \\
\hline & RMSE $\left(W^{-2}\right)$ & 13.06 & 14.66 & $16.73(15.85)$ & $18.78(17.91)$ \\
\hline \multirow[t]{2}{*}{ Albedo } & $\mathrm{R}$ & 0.78 & 0.62 & $0.85(0.86)$ & $0.67(0.70)$ \\
\hline & RMSE & 0.10 & 0.12 & $0.09(0.09)$ & $0.10(0.09)$ \\
\hline \multirow{2}{*}{$\begin{array}{l}\text { Relative snow } \\
\text { height }\end{array}$} & $\mathrm{R}$ & 0.68 & 0.94 & $0.72(0.75)$ & $0.80(0.69)$ \\
\hline & RMSE (m) & 0.60 & 0.59 & $0.39(0.41)$ & $0.32(0.27)$ \\
\hline
\end{tabular}

The statistics for the evaluation period were calculated one time for the entire time series and a second time for the time series excluding the optimization period.

temperature assuming a final surface emissivity of 0.99 , following Noël and others (2018) (Table 2).

To calculate the turbulent heat fluxes, COSIPY assumes a linear roughness length increase with time following Mölg and others (2009). The maximum increase from a fresh snow value of $0.5 \mathrm{~mm}$ to a firn value of $1.7 \mathrm{~mm}$ (Smeets and van den Broeke, 2008; Fausto and others, 2016) occurs if there is no new snow addition over a specified time window, which has the same length as the albedo aging factor (Mölg and others, 2009). A value of $3.5 \mathrm{~mm}$ is assumed for bare ice (Cullen and others, 2014). The stability influence on the sensible and latent heat fluxes is based on the Richardson number (Table 2; Braithwaite, 1995).

Surplus energy results in ablation. If the surface temperature is below $273.16 \mathrm{~K}$, only sublimation can occur. If the surface temperature exceeds the freezing point, it is set to a melting temperature of $273.16 \mathrm{~K}$ and the excess energy is translated into melt energy (Sauter and others, 2020). Aging snow layers decrease their height due to compaction and densification. The density calculation with the 'Boone' method is described in Essery and others (2013). Thereby, the density threshold of ice is $800 \mathrm{~kg}$ $\mathrm{m}^{-3}$ (Herron and Langway, 1980). The threshold of firn is derived after manually testing parameter combinations following the tested range in Cullen and others (2014) from 400 to $500 \mathrm{~kg}$ $\mathrm{m}^{-3}$. A minimum firn density of $400 \mathrm{~kg} \mathrm{~m}^{-3}$ was selected as it produces results closest to the observations (Table 2).

\subsubsection{COSIPY-WRF configuration}

The final COSIPY-WRF run was initiated on 15 July 2014. For the COSIPY-WRF simulations, the constant bottom-layer temperature was $258.7 \mathrm{~K}$ (the mean value for the observations at both AWSs) and was run with only the final set of parameters after the manual optimization. The first $15 \mathrm{~d}$ are regarded as a spin-up and are not included in the analysis. The spin-up includes the last 2 weeks of July where no snow accumulation was modeled or observed. The analyzed COSIPY-WRF output starts from 1 August 2014 (Table 1). At this time there is no fresh snow and minimal old snow observed and modeled at the glacier surface facilitating the initialization process of the model. The comparison against SEB terms and SMB from PROMICE AWSs is conducted for hourly values, except for albedo, for which a daily mean value is calculated. Albedo values are calculated as the sum of the observed outgoing shortwave radiation divided by the sum of the observed incoming shortwave radiation in $1 \mathrm{~d}$.
This approach is suggested by Oerlemans and Knap (1998) to reduce errors from hours of low solar elevation.

\section{Results and discussion}

\subsection{Model evaluation}

\subsubsection{Optimization period (January to December 2015)}

In order to optimize the model set up, all time steps of year 2015 (1 January to 31 December) are evaluated according to the correlation coefficient $(R)$ and the root mean square error (RMSE) to the PROMICE AWSs (Table 3). COSIPY-WRF simulates the observed conditions at both AWSs well in the optimization period. The model results agree with the measurements with relatively high significant correlation coefficients and a low RMSE (Table 3). For surface temperature, COSIPY-WRF archives a performance comparable to Huintjes and others (2015) $(R=0.95, \mathrm{RMSE}=$ $3.44 \mathrm{~K}$ for KPC-L, and $R=0.94$, RMSE $=2.03 \mathrm{~K}$ for KPC-U, compared with $R=0.98, \mathrm{RMSE}=2.12 \mathrm{~K}$ in Huintjes and others, 2015). The evaluation statistics for albedo $(R=0.78, \mathrm{RMSE}=0.10$ for KPC-L, and $R=0.62, \mathrm{RMSE}=0.12$ for KPC-U) compare well with the statistics archived by Mölg and others (2008) $(R=0.69$, RMSE $=0.10)$. This suggests a reasonable level of optimization.

\subsubsection{Model evaluation from August 2014 to December 2018} A longer-term model evaluation of COSIPY-WRF is conducted for the period from 1 August 2014 to 31 December 2018. The statistical comparisons are also included in Table 3; a visual comparison is presented in Figures 2 and 3 for KPC-L and KPC-U, respectively. The comparison against the observation from PROMICE AWSs reveals a good agreement of COSIPY-WRF with the observed surface temperature $(R=0.92$, RMSE $=4.46 \mathrm{~K}$ for KPC-L, and $R=0.90$, RMSE $=5.13 \mathrm{~K}$ for KPC-U) and outgoing longwave radiation $\left(R=0.92, \mathrm{RMSE}=16.73 \mathrm{~W} \mathrm{~m}^{-2}\right.$ for $\mathrm{KPC}-\mathrm{L}$, and $R=0.91$, RMSE $=18.78 \mathrm{~W} \mathrm{~m}^{-2}$ for KPC-U) (Figs $2 \mathrm{a}, \mathrm{b}, 3 \mathrm{a}, \mathrm{b})$. For both variables, the simulated time series follow the annual cycle of the measurements and meet the values relatively accurately. The statistical evaluation for the surface temperature is similar to the evaluation in Sauter and others (2020). Statistics for the outgoing longwave radiation are similar to those considered as good in Noël and others $(2018 ; R=0.98$ and $\mathrm{RMSE}=14.20 \mathrm{~W} \mathrm{~m}^{-2}$ at their station S5). When excluding the optimization period from the evaluation period there is no systematic decrease in the model performance (Table 3 ).

The albedo is modeled with a relatively high correlation coefficient of $R=0.85$ for KPC-L and $R=0.67$ for KPC-U (Figs $2 c, 3 c$; Table 3). At KPC-L, the decrease in albedo during summer, when ice is exposed, is delayed in the simulations (Fig. 2c). This is a result of finding the best albedo parameters valid for the entire $79 \mathrm{~N}$ Glacier. To meet the KPC-L albedo values, a lower ice albedo and a higher scaling factor would produce a better model fit. However, a higher ice albedo and a lower albedo aging scaling factor produce a better agreement with the KPC-U albedo values. A similar difficulty in albedo parameterization choice for a large heterogeneous ice surface was identified by Noël and others (2018). In previous studies, a better agreement in albedo values between observations and simulations were achieved by advancing the albedo parameterization of Oerlemans and Knap (1998). For instance, Helsen and others (2017) included both wet and dry snow albedos and various albedo aging factors. However, COSIPY does not currently have the option to choose wet vs dry albedos; therefore, we selected the most appropriate albedo values based on manual optimization of the model (Section 2.4.1 and Table 2).

In terms of snow height change, an offset is evident at both stations (Figs 2d, 3d). Especially at KPC-L, the modeled snow 


\section{PWRF forced COSIPY - Model Evaluation against KPC-L}

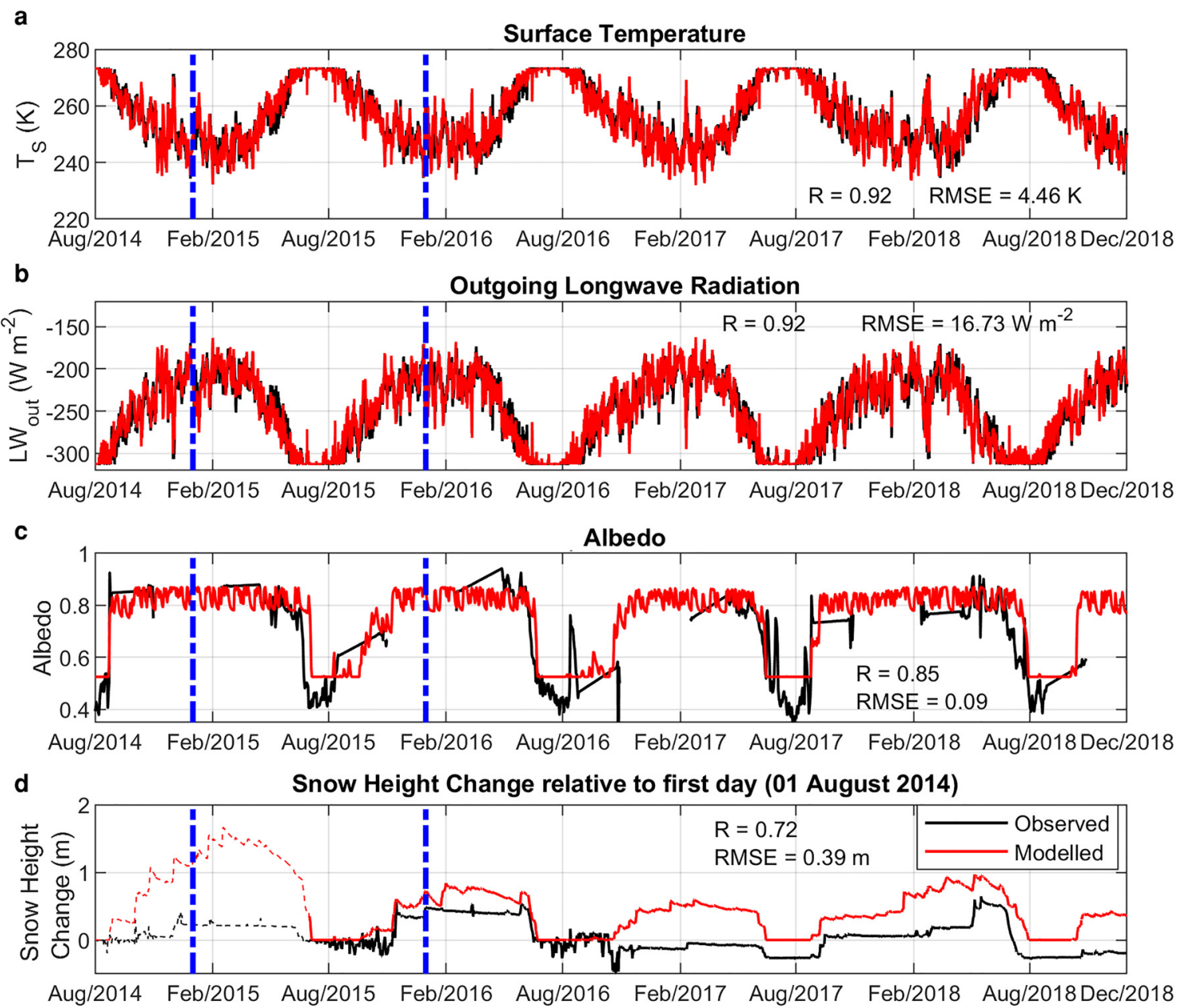

Fig. 2. Model evaluation against the KPC-L of hourly surface temperature (a), hourly outgoing longwave radiation (b), daily shortwave albedo (c) and accumulated hourly surface height change relative to the first time step (d). The time period is 1 August 2014 00:00 to 31 December 2018 23:00 LT. The blue-dashed lines indicate the start and end time of the optimization period. Due to a measurement error of the SR50 sensor for the snow height change (stripping), the time before 1 July 2015 was excluded from evaluation for the snow height evaluation. Snow height can drop below zero due to a small initial snow layer at the observation site.

height is too high in winter 2015. This is partly attributed to errors in the measurements during the accumulation period. The albedo and snow height at KPC-U remain high, indicating snow cover, whereas at KPC-L, snow height is much lower despite the high albedo value. Note that the values in Figures 2d, 3d can be negative as it is a relative change since the first date of the simulation (1 August 2014) when a small layer of snow was present on the surface. The sonic rangers used to measure the distance between the surface and the sensor have a membrane which deteriorates over time and produces erroneous values (personal communication from van As D, 22 August 2019), which is a known potential problem with these instruments (Mölg and others, 2020). Therefore, a number of time steps from August 2014 until July 2015 were left out while calculating the evaluation statistics resulting in an RMSE of $0.39 \mathrm{~m}$ (Fig. 2d). COSIPY-WRF still overestimates the snow height observations at KPC-U but results in a smaller RMSE of $0.32 \mathrm{~m}$ compared to the RMSE at KPC-L (Fig. 3d). After summer 2015, the agreement of modeled and observed snow height improves for both PROMICE AWSs. A positive model bias in snow height can also result from a number of things, including an underestimation of the density by the parameterization. Due to the large area of $79 \mathrm{~N}$ Glacier, finding a valid density parameter is difficult, as no density observations are available for this location. We tested both the 'Bonne' and 'Vionnet' parameterizations available in COSIPY and found higher agreement with observations for the Boone method. For the final run, the 'Boone' method was used as this was also reported to produce the best fit in previous studies (e.g. Essery and others, 2013). We chose this parameterization, despite having no observations to assess its validity for the $79 \mathrm{~N}$ Glacier region. Issues in snow height simulation also rise from the effects of snowdrift that are not simulated by PWRF. Previous studies have shown a significant effect of snowdrift on the snow height in eastern Greenland (Hasholt and others, 2003).

Figure 4 compares the modeled height change with the observations from the ablation stakes. Negative values point to ablation and decreasing surface height and positive values indicate accumulation and increasing surface height between July 2017 and July 2018. COSIPY-WRF overestimates ablation at some of the stake locations. At the glacier margin (five stakes; red points in Fig. 4), the modeled ablation is stronger compared to the measurements resulting in an RMSE of $0.97 \mathrm{~m}$. At the stakes near the grounding line (blue points in Fig. 4), this offset decreases. Here, the COSIPY-WRF results agree better with the observations $(\mathrm{RMSE}=0.32 \mathrm{~m})$. Some ablation stakes at higher altitudes point to either ablation or accumulation (five stakes: black points in Fig. 4). COSIPY-WRF simulates ablation well at the stakes affected by a decreasing surface. However, the model results in a positive MB at only one of the three sites with observed accumulation. This points to a modeled 2017-18 ELA that is too high. 


\section{PWRF forced COSIPY - Model Evaluation against KPC-U}

a

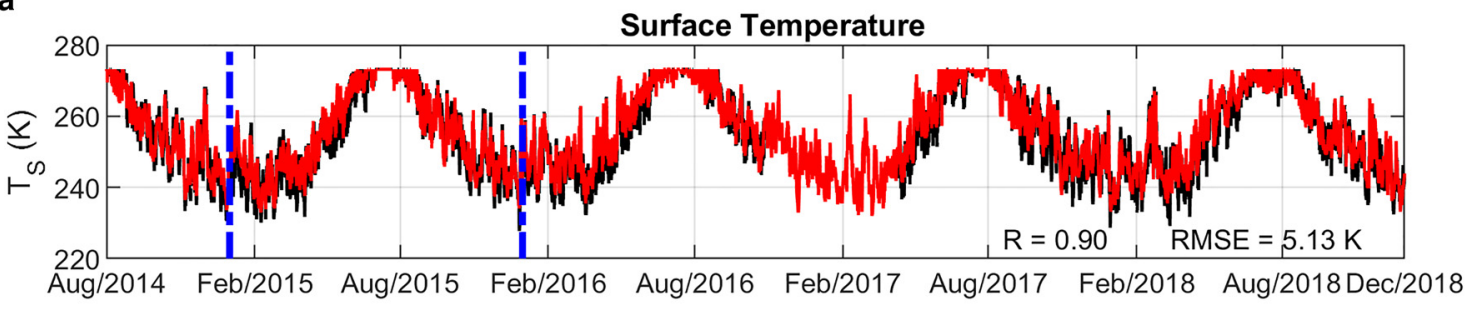

b

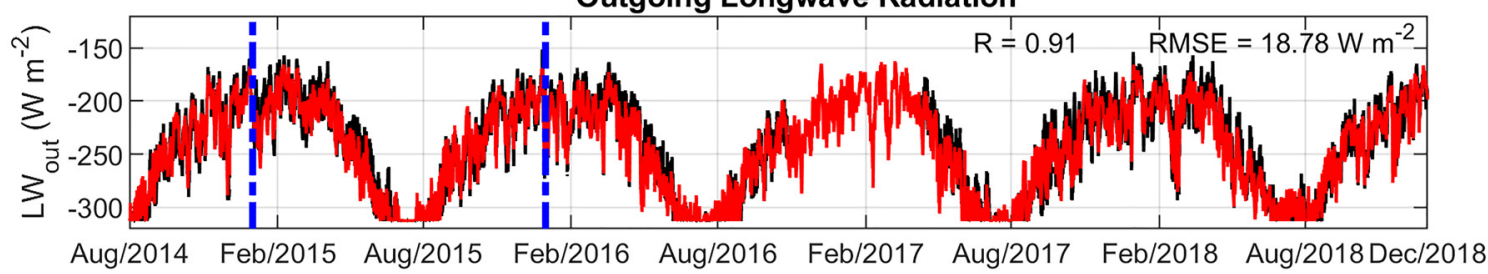

$\mathbf{C}$

Albedo

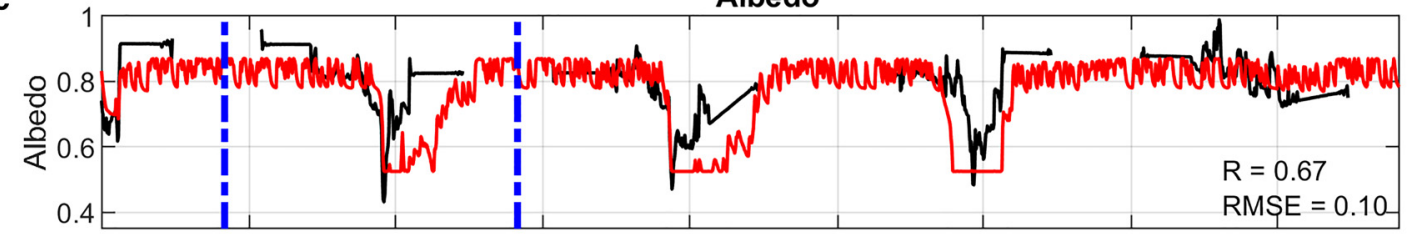

Aug/2014 Feb/2015 Aug/2015 Feb/2016 Aug/2016 Feb/2017 Aug/2017 Feb/2018 Aug/2018Dec/2018

d

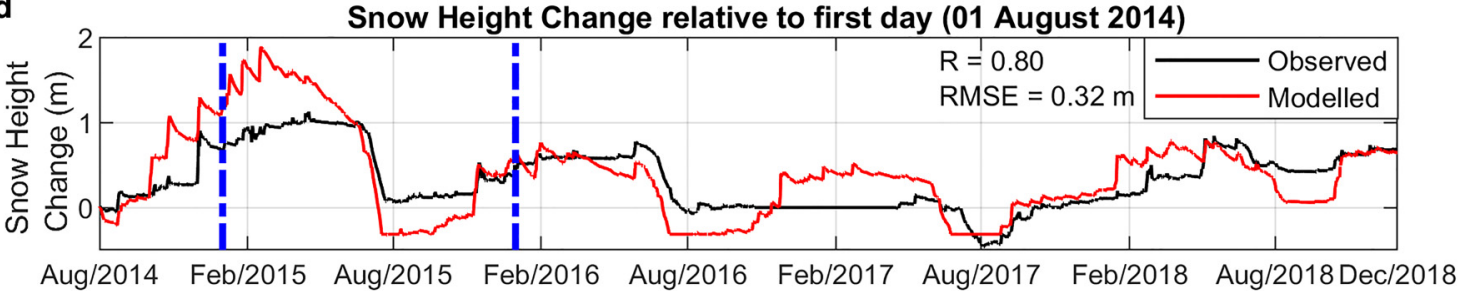

Fig. 3. Model evaluation against PROMICE the KPC-L AWS of hourly surface temperature (a), hourly outgoing longwave radiation (b), daily shortwave albedo (c) and accumulated hourly surface height change relative to the first time step (d). The time period is 1 August 2014 00:00 to 31 December 2018 23:00 LT. The blue-dashed lines indicate the start and end time of the optimization period. Snow height can drop below zero due to a small initial snow layer at the observation site.

Altogether, this leads to an RMSE of $0.67 \mathrm{~m}$ in the high-altitude group. The errors can be attributed to various reasons, such as measurement error related to tidal movement of the floating parts of the glacier tongue and GPS errors in elevation (see Section 2.3.2) (Reeh and others, 2000; Joughin and others, 2010; personal communication Zeising, 5 February 2020). The inaccuracy of the GPS sensors at the ablation stakes makes it difficult to find the exact gridpoint for the comparison with COSIPY-WRF (personal communication Zeising, 5 February 2020).

In spite of these significant measurement uncertainties, the simulated height change agrees relatively well with the observations. The model fit is highest at locations near the grounding line. The RMSE increases toward the lower areas of the floating tongue and toward the ELA. The floating tongue is highly crevassed and features many small melt ponds and channelized melt areas (Hochreuther and others, 2021) making it difficult to find appropriate places for stake observations. The ELA in the 2017-18 ablation period was lower than that in previous years, as the accumulation during winter 2017 to 2018 was more intense than previous years (Turton and others, 2020; Section 3.3), which could be partially responsible for a poorer agreement between observations and simulations at the lower elevations. All in all, the evaluation against PROMICE AWSs and ablation stake measurements shows that COSIPY-WRF in its current configuration can offer a realistic estimate of SMB and SEB of the $79 \mathrm{~N}$ Glacier and is therefore analyzed further in Section 3.2.

\section{2. $S M B$ and $I M B$}

The modeled SMB is illustrated in Figure 5. The 79N Glacier features distinct patterns regarding the spatial distribution of annual SMB. The floating tongue is prone to negative SMB in all simulated years. There are variations in the estimates regarding the ELA and the extent of ablation in higher regions. Between September 2014 and August 2017, negative SMB regions exceed $1000 \mathrm{~m}$ a.s.l. In the $2014-15$ period, SMB is negative up to an altitude of $1300 \mathrm{~m}$ a.s.l., however annual SMB total is small in magnitude accumulating to $\sim-13.56 \times 10^{6} \mathrm{~kg} \mathrm{a}^{-1}$ (Fig. 5a). The mass loss intensifies in the 2015-16 and 2016-17 periods, with annual SMB values of $-25.51 \times 10^{6}$ and $-29.68 \times 10^{6} \mathrm{~kg} \mathrm{a}^{-1}$, respectively (Figs 5b, c). Lower annual ablation in $2017-18$ at the glacier tongue is depicted in Figure 5d. In the 2017-18 period, annual accumulation at the surface is evident already at $500 \mathrm{~m}$ a.s.l. In this year, SMB accumulates to $\sim+5.75 \times 10^{6} \mathrm{~kg} \mathrm{a}^{-1}$.

Often, a negative TMB results in enhanced meltwater production. The surface water collects into meltwater ponds or supraglacial lakes, as seen on the surface of $79 \mathrm{~N}$ (Leeson and others, 2015; Ignéczi and others, 2016; Hochreuther and others, 2021). From there, a portion of meltwater evaporates, refreezes or runs off. Meltwater that penetrates the snowpack can either refreeze englacially, be collected in subglacial lakes or runs off at the base. The latter can lubricate the bedrock and can accelerate the ice flow inducing instability to other parts of the glacier 


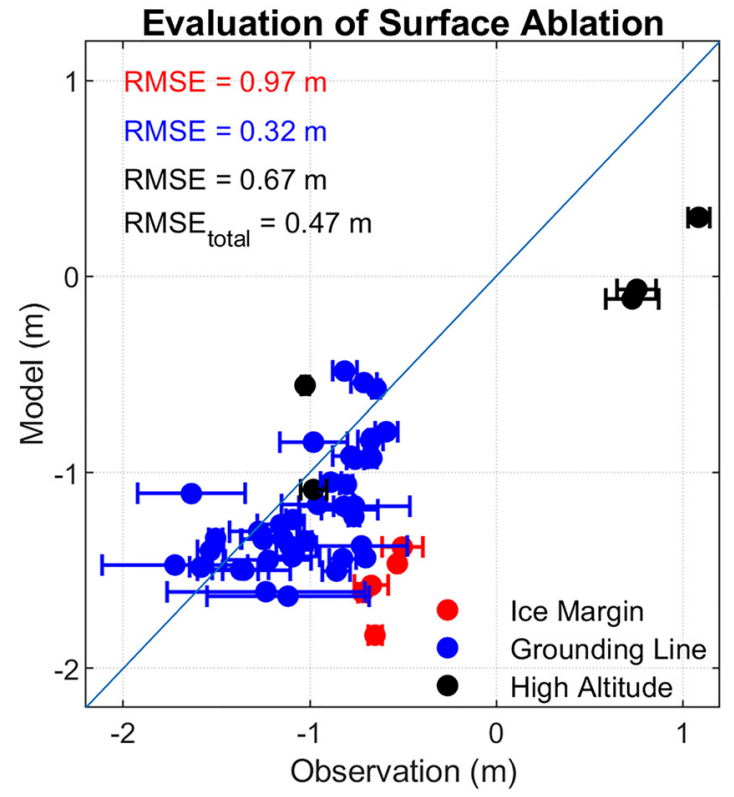

Fig. 4. Comparison of the modeled glacier height change with the GPS measurements at the ablation stakes from AWI. At each site, four stakes were deployed to prevent data loss in case of the failure of one stake and to provide error estimates. The error bars indicate the SD of the measured values at each site. Coloring shows reference to the location of the measurement sites like in Figure 1 (red: ice margin, blue: grounding line, black: high altitude region).

(Carr and others, 2013; Rathmann and others, 2017; Bevis and others, 2019). Figure 6 illustrate the portion of surface meltwater that refreezes, runs off, evaporates or is stored in the snowpack (Figs $6 a, b, c, d$ ). Furthermore, the contribution of SMB and IMB to TMB is illustrated. Figures $6 \mathrm{e}, \mathrm{f}, \mathrm{g}$ h depict the simulated cumulative annual IMB - refreeze minus subsurface melt - and SMB - snowfall and deposition minus surface melt, sublimation and evaporation - contributing to the TMB of the $79 \mathrm{~N}$ Glacier. Surface melt is a dominant factor determining ablation at the surface (Section 3.3).

The major portion of the surface melt contributes to the runoff in all years, whereas evaporation is suppressed because of the low temperatures in the region (Fig. 9b in Appendix C). As a result, only $1 \%$ of the surface meltwater evaporates. Furthermore, a considerable part of meltwater is stored inside the snow layers. Schröder and others (2020) found evidence for liquid water retention under ice lenses and snow throughout the winter in our study area, which confirms that not all meltwater refreezes. Refreezing is more dominant in 2014-15 and 2017-18. This may be related to cooler climate conditions and low surface temperatures, which promote fast refreezing of meltwater before it runs off (Figs 9a, b in Appendix C).

Although during the $2014-15$ and the $2017-18$ periods (Figs $6 e, h), I M B$ is the dominant factor for the TMB, the SMB does dominate over IMB in the periods from 2015-16 to 2016-17 (Figs 6f, g). The modeled TMB remains negative throughout the simulated time. In the years in which IMB is more negative than SMB, less than two-thirds of the meltwater contribute to the surface runoff (Figs $6 \mathrm{a}, \mathrm{d}$ ). In contrast, $>85 \%$ of the total meltwater runs off in years when SMB contributes more to the TMB (Figs $6 \mathrm{~b}, \mathrm{c}$ ). The only year with a positive component of the MB is 2017-18, but estimated positive SMB is compensated by negative $\mathrm{IMB}$, resulting in an overall negative TMB.

SMB has a higher annual variability compared to IMB as it is more dependent on regional atmospheric conditions and its variability. Changes in meltwater runoff induce variabilities to the stability, the velocity and the total mass loss of the glacier
(Fettweis, 2007; Mayer and others, 2018; Bevis and others, 2019). The IMBIE Team (2020) supported that the meltwater production and runoff for the GrIS increased because of regional warming. Therefore, glacier-wide surface ablation can explain strong run off between 2015 and 2017. Furthermore, an overall negative $\mathrm{MB}$ in all periods agrees with Mouginot and others (2019). They identified an overall negative MB for the GrIS, which was largely due to internal and dynamic processes that did not allow accumulation due to surface processes even in years with positive SMB. This agrees with our findings for the 2017-18 period, when modeled positive SMB turns into a negative MB due to the IMB. Dynamical processes, such as iceberg calving or surging, are not included in the COSIPY model. However, during our study period, no major calving events were detected and $79 \mathrm{~N}$ is not a surge-type glacier, unlike its southerly neighbor, Storstrømmen (Mouginot and others, 2019).

\subsection{Interannual variability of the SMB}

The difference in SMB between the 2016-17 (Fig. 5c) and 201718 (Fig. 5d) years (which are the highest and lowest surface melt years in our study, respectively), prompted us to investigate the differences between the two years (hereafter '2017' and '2018'). TMB and SMB exhibit distinct features. Ablation is strongly reduced in 2018 concerning both the total and the surface ablation (Figs $7 \mathrm{~b}, \mathrm{~d}$ ), whereas accumulation does not show large differences (Fig. 7a, c). Snowfall and surface melt during the ablation period are prominent components of SMB (Figs 7e, f, j), whereas deposition and sublimation are less dominant (Figs $7 \mathrm{~g}, \mathrm{~h}, \mathrm{k}, \mathrm{l}$ ). Due to the overall low surface and $2 \mathrm{~m}$ air-temperature, surface melting is suppressed and ablation due to sublimation gains importance in the accumulation period and in high altitude bands (Figs 7i, k; Figs 9a, b in Appendix C).

Distinct and significant differences are evident regarding the strength of surface melt and snowfall (paired $t$-test). Although in 2017 intensive melting appears in the ablation period, the melting is reduced in 2018 (Fig. 7j). Simultaneously, snowfall increased at elevations below $1200 \mathrm{~m}$ in the ablation period of 2018 compared to 2017 (Fig. 7f). However, there was no significant difference in snowfall amount during the accumulation periods of the two years (Fig. 7e). Only in lower altitudes of the ablation zone does the surface melt exceed mass gain by snowfall, while snowfall accumulation is persistent, leading to a distinct and significant reduction in negative SMB values in 2018 compared to 2017 (paired $t$-test).

SMB features are also expressed by the SEB (Fig. 8). Energy surplus during the ablation period is caused by rising incoming shortwave radiation and decreasing albedo resulting in a high positive net shortwave radiation (Figs 8b, d, and Fig. 10b in Appendix $\mathrm{C})$, whereas in the accumulation period the shortwave radiation budget is near zero and albedo values are high (Figs $8 \mathrm{a}, \mathrm{c}$, and Fig. 10a in Appendix C; Fausto and others, 2016; Hahn and others, 2020). In the 2017 accumulation period, the longwave radiation is more negative at lower altitudes than in 2018. In the 2017 ablation period, a more negative longwave radiation is simulated at higher elevations. Overall, this leads to a weaker longwave radiation deficit in 2017 compared to 2018 (Figs 8e, f, and Fig. 10d in the Appendix C; Turton and others, 2019a). Sensible heat adds energy to the surface throughout the year (Figs $8 \mathrm{~g}, \mathrm{~h}$ ). Surface temperatures at the melting point initiate the conversion of excess energy to melt energy during the ablation period (Figs 81, Fig. 9a in Appendix C). The low longwave radiation flux coupled with a negative latent heat flux and a lack of energy input by shortwave radiation and by sensible heat suppresses melt energy, which approaches zero in all altitude bands in the accumulation period 2018 (Fig. 8k). 


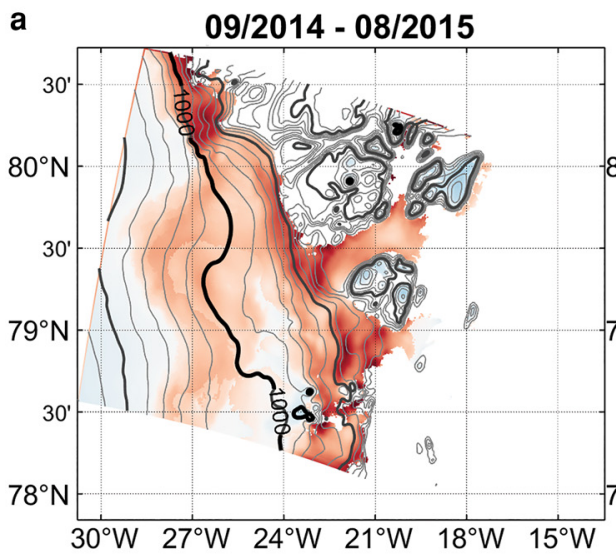

b $\quad 09 / 2015-08 / 2016$

c
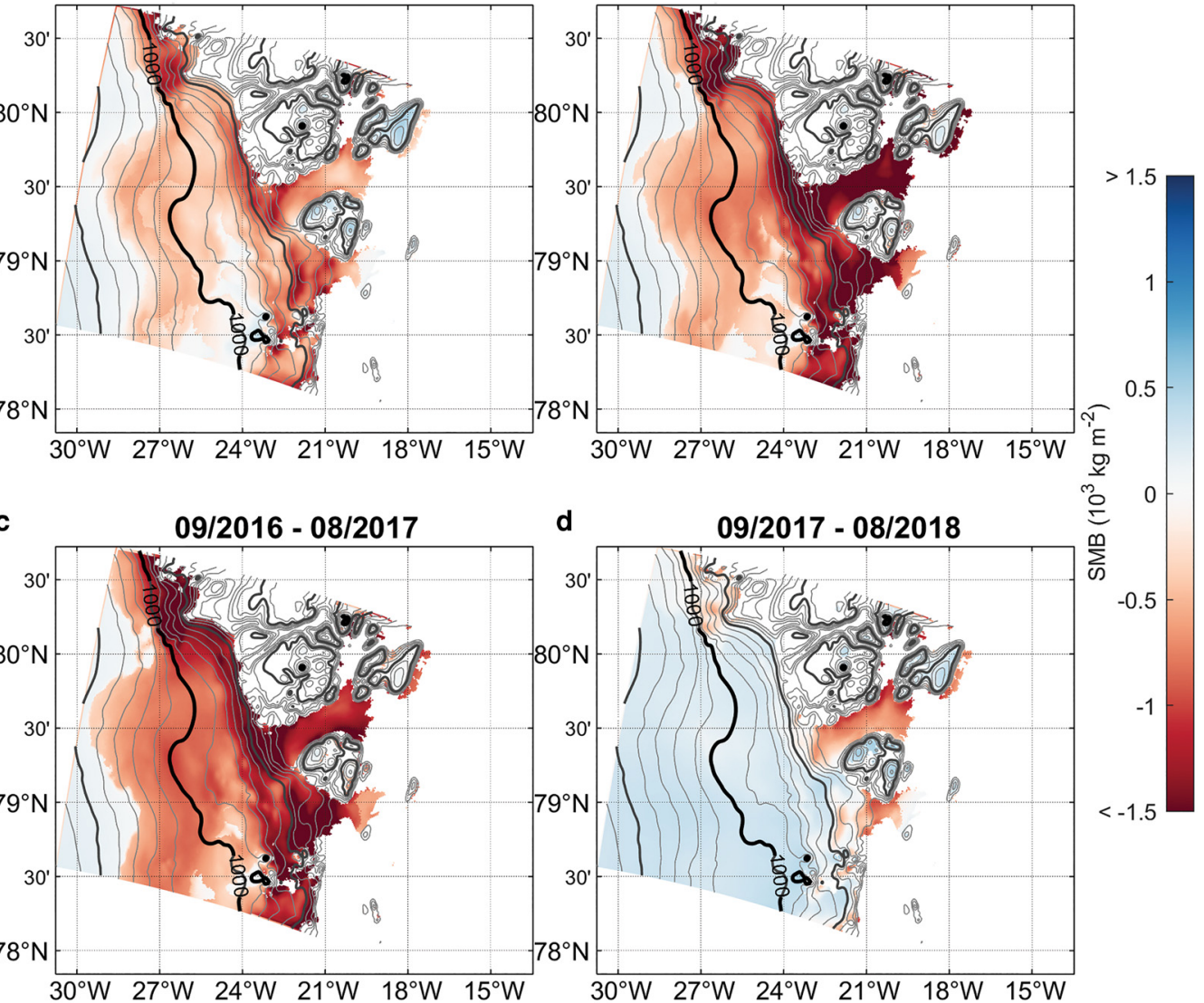

Fig. 5. Spatial distribution of the annual SMB from September to August of the following year starting 2014 (a), 2015 (b), 2016 (c) and 2017 (d). The contours indicate $100 \mathrm{~m}$ (gray) and $1000 \mathrm{~m}$ (black) altitude steps taken from WRF.

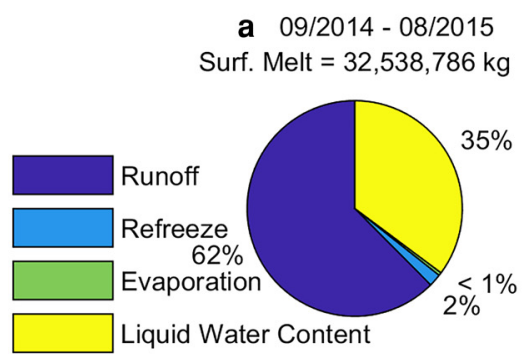

b $09 / 2015-08 / 2016$

Surf. Melt $=39,194,235 \mathrm{~kg}$

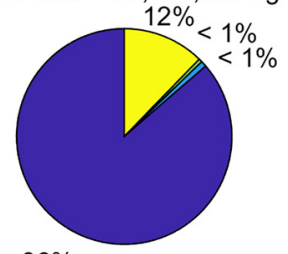

$86 \%$
C $09 / 2016-08 / 2017$

Surf. Melt $=40,934,872 \mathrm{~kg}$

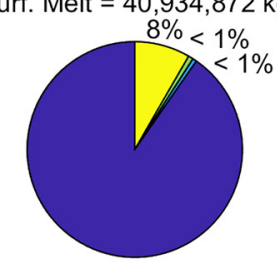

$90 \%$ d $09 / 2017-08 / 2018$

Surf. Melt $=10,352,351 \mathrm{~kg}$

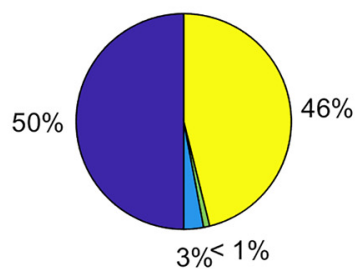

e $09 / 2014-08 / 2015$

f $09 / 2015-08 / 2016$

g $09 / 2016-08 / 2017$

h $09 / 2017-08 / 2018$
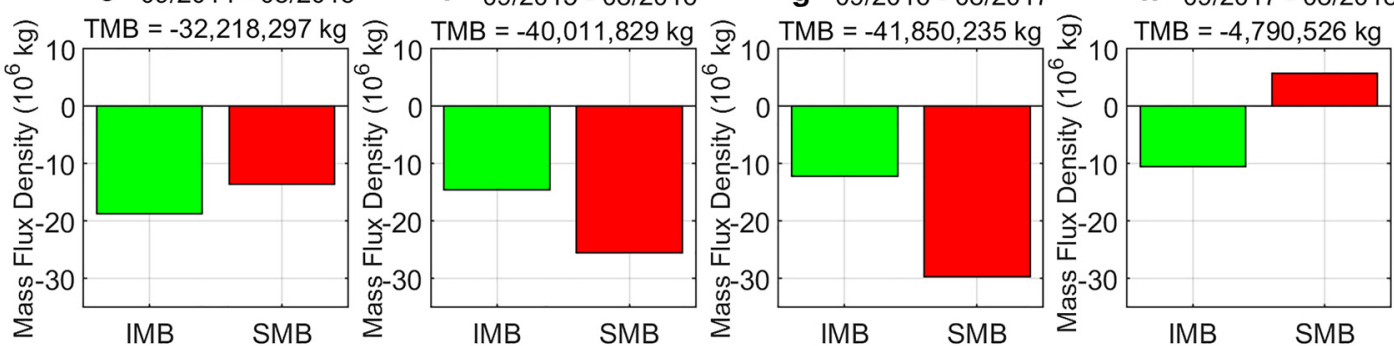

Fig. 6. The ratio of surface meltwater that contributes to runoff, refreeze, evaporation or remains in the snow layer as liquid water content from September to August of the following year starting 2014 (a), 2015 (b), 2016 (c) and 2017 (d). The bottom panels show the contribution of SMB and IMB to the TMB of the same periods starting 2014 (e), 2015 (f), 2016 (g) and 2017 (h).

In the ablation period of 2017, the snow layer melted entirely, including at higher altitudes, resulting in the exposure of large extents of ice surface. As a consequence, the albedo was reduced and more shortwave radiation was absorbed and therefore available for ablation processes in summer 2017; a causality chain known to induce strong variability in $\mathrm{MB}$ also in other climatic 


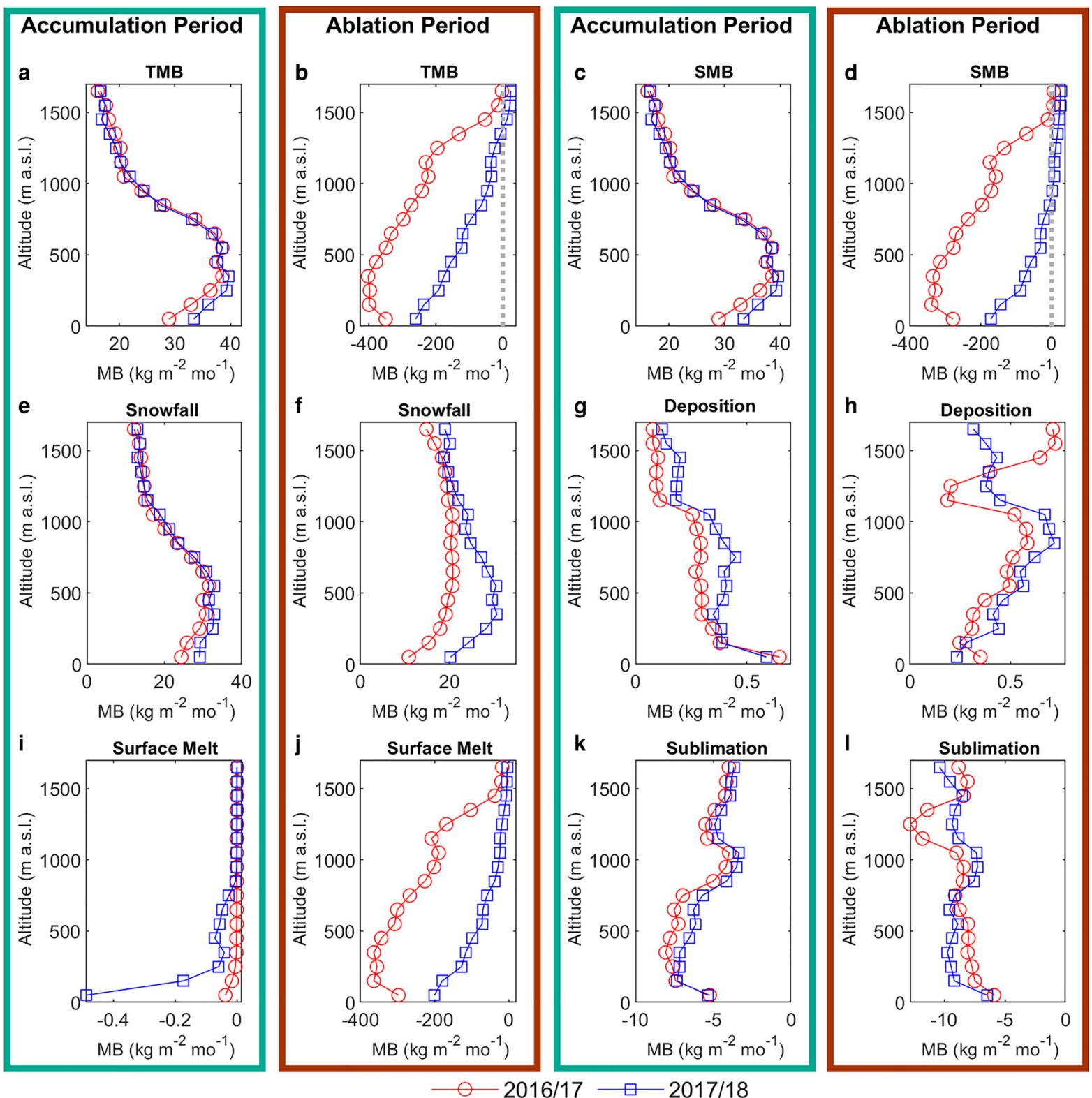

Fig. 7. Average vertical profile (altitude bands of $50 \mathrm{~m}$ ) of the TMB ( $a$ and $b$ ) and SMB (c and d), and the components of the modeled SMB. This includes snowfall from PWRF ( $e$ and $f$ ), deposition ( $g$ and $h$ ), surface melt ( $i$ and $j$ ) and sublimation ( $k$ and $l)$. The red line shows results for 2016-17 and the blue line shows results for 2017-18. The data are averaged over the accumulation periods (October 2016 to April 2017, and October 2017 to April 2018) in light blue boxes and over the ablation periods (May to September 2017 and May to September 2018) in brown boxes.

zones (Mölg and others, 2009). This albedo feedback also explains positive SMB in the 2017-18 period. Higher snowfall in lower altitudes increased the snow height, which caused higher albedo and a decreased shortwave radiation budget at the surface. A lower snowline resulted in higher albedo, which reduced the melt energy and dampened surface melting in summer 2018. This snowline-albedo feedback at the margins of the GrIS was described for the period 2001-2017 by Ryan and others (2019).

The COSIPY-WRF simulation points to a significantly warmer ablation period, especially in July, in terms of surface and air temperature in 2017 compared to 2018 in all altitude bands (paired $t$-test; Figs 9a, b in Appendix C). Additionally, wind speed and relative humidity from PWRF are significantly increased during both seasons in 2017 (paired $t$-test; Figs 9c, $d$ in Appendix C). The differences in wind speed at the altitude bands near the grounding line are the only non-significant points (Fig. 9c in Appendix C). The strong and persistent wind speed in July 2017 promotes the intensification of turbulent energy fluxes in the ablation period
(Figs $8 \mathrm{~h}, \mathrm{j}$ ). Those increases in importance to SMB as other ablation processes (e.g. surface melt; Fig. 8i) are suppressed due to low temperatures. The respective mass turnover by sublimation and deposition has less of an impact on the TMB, however (Figs $7 \mathrm{~g}, \mathrm{~h}, \mathrm{k}, \mathrm{l}$ ). The snowfall (Fig. 7b) has a much larger impact on $\mathrm{SMB}$, as seen over large parts of the glaciers in 2018 compared to 2017 (Figs 5c, d). In conclusion, less mass loss at the surface may be attributed to a significant increase in snowfall, and therefore albedo values, which was largely caused by a cooler regional climate in summer 2018 (The IMBIE Team, 2020).

\section{Conclusion}

The forcing of an SMB model with a high-resolution regional atmospheric model, PWRF, reproduced available observations reasonably well and enables more insights into mass changes in the remote area of the $79 \mathrm{~N}$ Glacier. The manual model optimization conducted to meet the climatic observations from two 

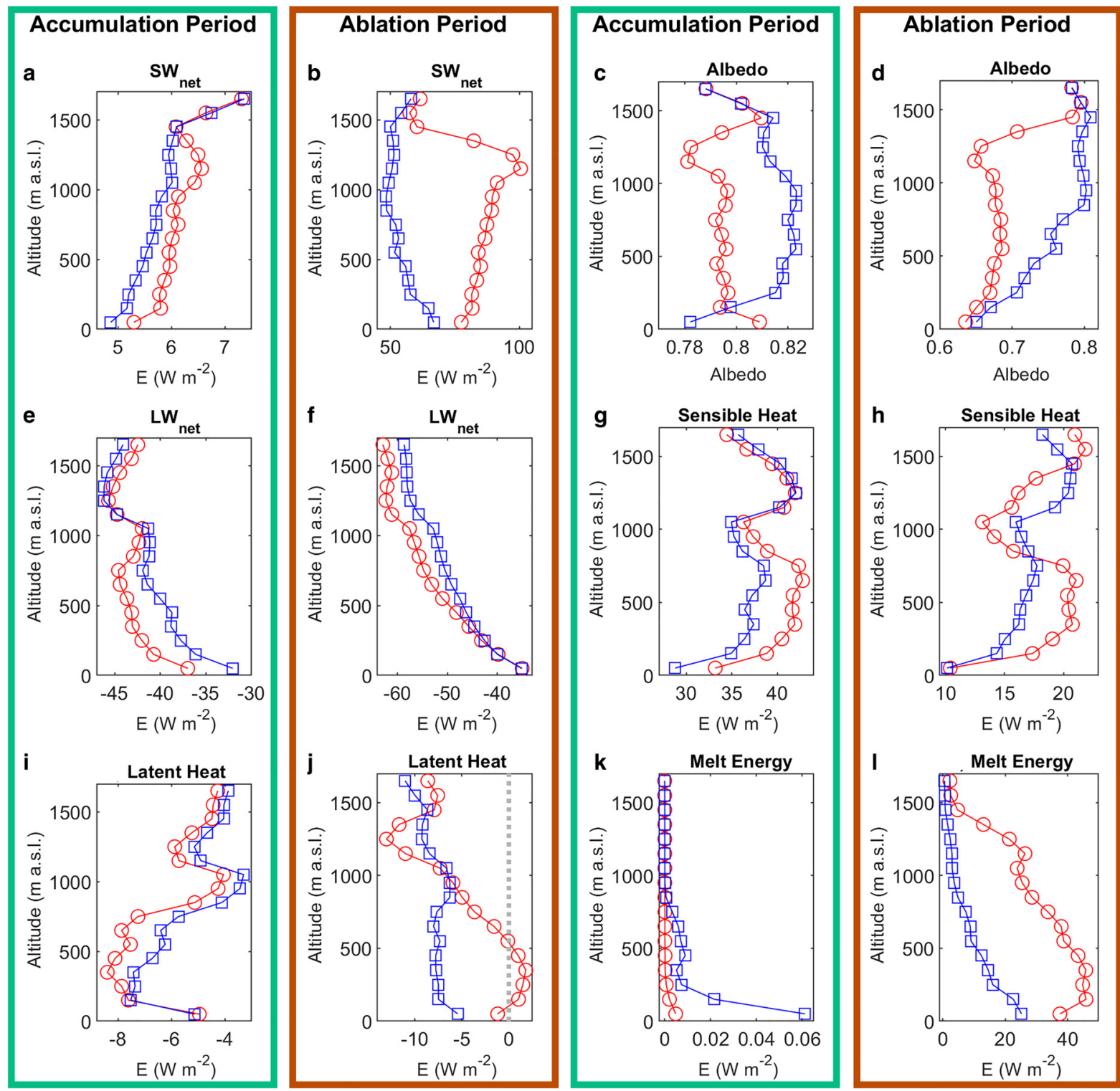

○-2016/17 - $2017 / 18$

Fig. 8. Average vertical profile (altitude bands of $50 \mathrm{~m}$ ) for the components of the SEB. This includes net shortwave radiation, SWnet (a and b), albedo (c and d), net longwave radiation, LWnet (e and f), sensible heat flux ( $g$ and $h$ ), latent heat flux ( $i$ and $j$ ) and melt energy ( $k$ and $l$ ) from COSIPY-WRF. The red line shows results for 2016-17 and the blue line shows results for 2017-18. The data are averaged over the accumulation periods (October 2016 to April 2017 , and October 2017 to April 2018) in light blue boxes and over the ablation periods (May to September 2017 and May to September 2018) in brown boxes.

PROMICE AWSs, however, also revealed problems in the parameterization for a large area. Often, input to SMB models, especially on smaller glaciers, comes from one or a few in situ observation sites (Mölg and others, 2008; Sauter and others, 2020). In this case, we attempted to find the best parameter selection for two stations, one in the ablation zone and one near the ELA, with quite different climatic characteristics. In addition, the simulation of snowfall and the related accumulation was a critical factor (Section 3.1). However, the modeled data from COSIPY-WRF were found to be suitable for a first detailed analysis of MB processes as response to atmospheric features.

SMB observations in this remote region are sparse and often plagued with difficulties. Independent stake data were only available for 1 year and were affected by tidal variations and GPS inaccuracies. However, our estimates of $\sim 2 \mathrm{~m}$ mass loss on the floating tongue were also found in similar magnitude for NEGIS and 79N by Khan and others (2014). At the grounding line, the model results are more comparable with observations. Partially, this could be due to reduced tidal influence, but may also be due to parameter selections based on the KPC-L station, which is close to this location (Fig. 1).

The present results indicate stronger variability of ablation processes compared to accumulation processes on interannual timescale in the study domain. SMB features are dominated by ablation over the $79 \mathrm{~N}$ Glacier in $2014-17$ and turn positive in 2018. A major reason for this change in sign of the SMB is a strong variability in surface melt rates. In intense ablation years (September 2015 to August 2017) the mass loss due to surface ablation dominates the impact of IMB, and a major part of the meltwater contributes to the surface runoff. This finding is reversed in years with less overall ablation (September 2014 to August 2015) or positive SMB (September 2017 to August 2018). In those years, dominant factors inducing mass loss are components of IMB while SMB is small or positive. Also, most of the meltwater does not contribute to the surface runoff in those years. The TMB in the analyzed period remains negative (Fig. 6). 
The COSIPY-WRF results reveal a substantial interannual variability in surface ablation, such as the reduced values in 2018, which can be explained by the effects of a cooler regional climate. The main differences between 2018 and the previous years with more intense overall ablation are increased snowfall, decreased surface melt and consequently higher albedo and lower net shortwave radiation budget in summer 2018. This difference effects large parts of the higher regions of the $79 \mathrm{~N}$ Glacier, while being insignificant on the glacier tongue. Therefore, the climate in the lower ablation zone is potentially less influential over interannual SMB variability.

The low overall temperatures in this region suppress the ablation processes such as surface melting. Especially in the accumulation period, when the mean temperatures do not exceed the melting point, sublimation and deposition rise in importance, but remain in a low quantity. Melting at the NEGIS and 79N including the floating tongue occurs almost exclusively in June to August when net shortwave radiation is positive. In conclusion, the presented dataset reproduces SMB and SEB at the 79N Glacier reasonably well and highlights the large spatial and interannual variability of SMB and the individual components. The high resolution of SMB output is beneficial for future investigation into interactions between specific atmospheric features or extreme events, and the mass and energy balance of the $79 \mathrm{~N}$ Glacier.

Acknowledgements. We thank Ole Zeising from the Alfred-Wegener Institute (AWI) for providing the data from the ablation stakes at the $79 \mathrm{~N}$ Glacier and for additional information and communication throughout the project. Thanks are also to Prof. Jason Box for his information on the calving of $79 \mathrm{~N}$. This study was supported by the German Federal Ministry for Education and Research (BMBF) with grant number 03F0778F. We acknowledge the High-Performance Computing Centre (HPC) at the University of Erlangen-Nürnberg's Regional Computation Centre (RRZE), for their support and resources while running the COSIPY simulations. Daily average values of the SMB components from July 2014 to December 2018 are available online and open access at: www.doi.org/10.5281/zenodo.4434259 . We express our thanks to the two anonymous reviewers and the editor for providing reviews of the paper, which benefitted from their critiques.

Author contributions. M.T.B. conducted optimization, simulation and evaluation of the COSIPY-WRF model and wrote the manuscript. J.V.T. designed the study. T.S. provided assistance in the setup and running of the model. T.M. assisted with model optimization and evaluation. J.V.T, T.S. and T.M. contributed to writing the manuscript and discussion of the results.

Conflict of interest. The authors confirm that they have no conflict of interest.

\section{References}

Andersen JK and 17 others (2019) Update of annual calving front lines or 47 marine terminating outlet glaciers in Greenland (1999-2018). Geology of Greenland Survey Bulletin 43, e2019430202 doi: 10.34194/GEUSB- 201943-02-02.

Bevis M and 13 others (2019) Accelerating changes in ice mass within Greenland, and the ice sheet's sensitivity to atmospheric forcing. Proceedings of the National Academy of Sciences of the United States of America 116(6), 1934-1939 doi: 10.1073/pnas.1806562116 .

Bintanja R and van den Broeke MR (1995) The surface energy balance of Antarctic snow and blue ice. Journal of Applied Meteorology 34(4), 902924. doi: 10.1175/1520-0450(1995)034<0902:TSEBOA>2.0.CO;2

Bøggild CE, Brandt RE, Brown KJ and Watten SG (2010) The ablation zone in northeast Greenland: ice types, albedos and impurities. Journal of Glaciology 56(195), 101-113. doi: 10.3189/002214310791190776

Braithwaite RJ (1995) Aerodynamic stability and turbulent sensible-eat flux over a melting ice surface, the Greenland ice sheet. Journal of Glaciology 41(139), 562-571. doi: 10.3189/S002214300003488

Carr RJ, Stokes CR and Vieli A (2013) Recent progress in understanding marine-terminating Arctic outlet glacier response to climatic and oceanic forcing: twenty years of rapid change. Progress in Physical Geography 37 (4), 436-467. doi: 10.1177/0309133313483163
Cullen NJ, Mölg T, Conway J and Steffen K (2014) Assessing the role of sublimation in the dry snow zone of the Greenland ice sheet in a warming world. Journal of Geophysical Research Atmosphere 119(11), 6563-6577. doi: 10.1002/2014JD021557

Essery R, Morin S, Lejeune Y and Ménard CB (2013) A comparison of 1701 snow models using observations from an alpine site. Advances in Water Resources 55, 131-148. doi: 10.1016/j.advwatres.2012.07.013

Ettema J and 6 others (2009) Higher surface mass balance of the Greenland ice sheet revealed by high-resolution climate modeling. Geophysical Research Letters 36(12), D06116. doi: 10.1029/2009GL038110

Fausto RS and 5 others (2016) The implication of nonradiative energy fluxes dominating Greenland Ice Sheet exceptional ablation area surface melt in 2012. Geophysical Research Letters 43(6), 2649-2658. doi: 10.1002/ 2016GL067720

Fausto RS and van As D (2019) Programme for monitoring of the Greenland ice sheet (PROMICE): Automatic weather station data. Version: v03. Dataset published via Geological Survey of Denmark and Greenland doi: $10.22008 /$ promice/data/aws .

Fettweis X (2007) Reconstruction of the 1979-2006 Greenland ice sheet surface mass balance using the regional climate model MAR. The Cryosphere $\mathbf{1}$ (1), 21-40. doi: 1.5194/tc-1-21-2007

Hahn LC, Storelvmo T, Hofer S, Parfitt R and Ummenhofer CC (2020) Importance of orography for Greenland cloud and melt response to atmospheric blocking. Journal of Climate 33(10), 4187-4206. doi: 10.1175/JCLI- D-19-0527.1

Hahn L, Ummenhofer CC and Kwon YO (2018) North Atlantic natural variability modulates emergence of widespread Greenland melt in a warming climate. Geophysical Research Letters 45, 9171-9178. doi: 10.1029/2018GL079682

Hasholt B, Liston GE and Knudsen NT (2003) Snow-distribution modelling in the Ammassalik region, South East Greenland. Hydrological Research 34 (1-2), 1-16. doi: 10.2166/nh.2003.0025

Helsen MM and 7 others (2017) On the importance of the albedo parameterization for the mass balance of the Greenland ice sheet in EC-earth. The Cryosphere 11(4), 1949-1965 doi: 10.5194/tc-11-1949-2017.

Herron MM and Langway Jr CC (1980) Firn densification: an empirical model. Journal of Glaciology 25(93), 373-358 doi: 10.3189/\$0022163000015239

Hines KM and Bromwich DH (2008) Development and testing of polar weather research and forecasting (WRF) model. Part 1: Greenland Ice Sheet meteorology. Monthly Weather Review 136(6), 1971-1989. doi: 10.1175/2007MWR2112.1

Hochreuther P, Neckel N, Reimann N, Humbert A and Braun M (2021) Fully automated detection of supraglacial lake area for Northeast Greenland using sentinel-2 time-series. International Journal of Remote Sensing 13(2), 205. doi: 10.3390/rs13020205

Huintjes E and 9 others (2015) Evaluation of a coupled snow and energy balance model for Zhadang glacier, Tibetan Plateau, using glaciological measurements and time-lapse photography. Arctic Antarctic and Alpine Research 47(3), 573-590 doi: 10.1657/AAAR0014-073.

Huybrechts P, Mayer C, Oerter H and Jung-Rothenhäusler F (1999) Climate change and sea level: Ice-dynamics and mass-balance studies on the Greenland ice sheet- EPIC3 Rep. on the Contribution of the Alfred Wegener Institute to EU Contract ENV4-CT95-0124, European Commission, DG XII, 18 pp. Available at https://epic.awi.de/id/eprint/3663/1/ Huy1999b.pdf.

Ignéczi A and 7 others (2016) Northeast sector of the Greenland Ice Sheet to undergo the greatest inland expansion of supraglacial lakes during the 21st century. Geophysical Research Letters 43(18), 9729-9738 doi: 10.1002/ 2016GL070338

The IMBIE Team (2020) Mass balance of the Greenland Ice sheet from 1992 to 2018. Nature 579, 233-239. doi: 10.1038/s41586- 019-0855-2

Jensen TS, Box JE and Hvidberg CS (2016) A sensitivity study of annual area change for Greenland ice sheet marine terminating outlet glaciers: 19992013. Journal of Glaciology 62(231), 72-81. doi: 10.1017/jog.2016.12

Joughin I, Smith BE, Howat IM, Scambos T and Moon T (2010) Greenland Flow variability from ice-sheet-wide velocity mapping. Journal of Glaciology 56(197), 415-430. doi: 10.3189/00224310792447734

Khan SA and 12 others (2014) Sustained mass loss of the northeast Greenland ice sheet triggered by regional warming. Nature Climate Change 4, 292-299 doi: $10.1038 /$ nclimate2161

Krieger L, Floricioiu D and Neckel N (2020) Drainage basin delineation for outlet glaciers of northeast Greenland based on sentinel-1 ice velocities and TanDEM-X elevations. Remote Sensing of the Environment 237, 111483. doi: 10.1016/J.rse.2019.111483 
Leeson AA and 6 others (2015) Supraglacial lakes on the Greenland ice sheet advance inland under warming climate. Nature Climate Change 5, 51-55 doi: 10.1029/NCLIMATE2463.

Lim YK and 7 others (2016) Atmospheric summer teleconnections and Greenland Ice Sheet surface mass variations: insights from MERRA-2. Environmental Research Letters 11, 024002 doi: 10.1088/1748- 9326/11/2/ 024002.

Mayer C and 8 others (2018) Large ice loss variability at Nioghalvfjerdsfjorden Glacier, Northeast-Greenland. Nature Communication 9(2768), 1-11. doi: 10. 138/s41467- 018-05180-x.

Mölg T and 8 others (2020) Mesoscale atmospheric circulation controls of local meteorological elevation gradients on Kersten Glacier near Kilimanjaro summit. Earth System Dynamics 11(3), 653-672 doi: 10.5194/esd 11-653-2020.

Mölg T, Cullen NJ, Hardy DR, Kaser G and Klok L (2008) Mass balance of a slope glacier on Kilimanjaro and its sensitivity to climate. International Journal of Climatology 28(7), 881-892. doi:10.1002/joc.1589

Mölg T, Cullen NJ, Hardy DR, Winkler M and Kaser G (2009) Quantifying climate change in the Tropical Midtroposphere over East Africa from glacier shrinkage on Kilimanjaro. Journal of Climate 22(15), 4162-4181. doi: 10 1175/2009JCLI2954.1

Mölg T, Maussion F and Scherer D (2014) Mid-latitude westeries as a driver of glacier variability in monsoonal high Asia. Nature Climate Change 4, 68 73. doi: 10.1038/NCLIMATE2055

Mölg T, Maussion F, Yang W and Scherer D (2012) The footprint of Asian monsoon dynamics in the mass and energy balance of a Tibetan glacier The Cryosphere 6(6), 1445-1461. doi: 10.5194/tc- 6-1445-2012

Mouginot J and 8 others (2019) Forty-six years of Greenland Ice sheet mass balance from 1972 to 2018. Proceedings of the National Academy of Sciences of the United States of America 116(19), 9239-9244 doi: 10.1073/pnas.1904242116.

Münchow A, Schaffer J and Kanzow T (2020) Ocean circulation connecting fram strait to glaciers off Northeast Greenland: mean flows, topographic Rossby waves, and their forcing. Journal of Physical Oceanography 50(2), 509-530. doi: 1.1175/JPO-D-19-0085.1

Noël B and 11 others (2018) Modelling the climate and surface mass balance of polar ice sheets using RACMO2 - Part 1: Greenland (1958-2016). The Cryosphere 12(3), 81-831 doi: 10.5194/tc- 12-811-2018

Noël B, van de Berg WJ, Lhermitte S and van den Broeke MR (2019) Rapid ablation zone expansion amplifies north Greenland mass loss. Science Advances 5(9), eaaw0123. doi: 10.1146/sciadv.aaw0123

Oerlemans J and Knap WH (1998) A 1 year record of global radiation and albedo in the ablation zone of Morteratschgletscher, Switzerland. Journal of Glaciology 44(147), 231-238. doi: 10.3189/S0022143000002574

Rathmann NM and 7 others (2017) Highly temporally resolved response to seasonal surface melt of the Zachariae and $79 \mathrm{~N}$ outlet glaciers in northeast Greenland. Geophysical Research Letters 44(19), 9805-9814 doi: 10.1002/ 2017GL074368

Reeh N, Mayer C, Miller H, Thomsen HH and Weidick A (1999) Present and past climate control on fjord glaciations in Greenland: implications for IRD-deposition in the sea. Geophysical Research Letters 26(8), 1039 1042. doi: 10.1029/1999GL900065

Reeh N, Mayer C, Olesen OB, Christensen EL and Thomsen HH (2000) Tidal movement of Nioghalvfjerdsfjorden glacier, northeast Greenland: observations and modelling. Annals of Glaciology 31, 111-117.

Ryan J C and 6 others (2019). Greenland Ice sheet surface melt amplified by snowline migration and bare ice exposure. Science Advances 5(3), eaav3738 doi: $10.1126 /$ sciadv.eaav3738
Sauter T and Arndt A (2020) Coupled snowpack and ice surface energy and mass balance model in Python (COSIPY) doi: 10.5281/zenodo.36132921 In URL: https://cryotools.github.io/cosipy/ (last accessed on April 14, 2020).

Sauter T, Arndt A and Schneider C (2020) COSIPY v1.3 - an open-source coupled snowpack and ice surface energy and mass balance model. Geoscientific Model Development 13(11), 5645-5662. doi: 10.5194/gmd13-5645-2020

Schaffer J and 6 others (2016) A global, high-resolution data set of ice sheet topography, cavity geometry, and ocean bathymetry. Earth System Science Data 8(2), 543-557 doi: 10.5194/essd- 8-543-2016.

Schaffer J and 6 others (2017) Warm water pathways toward Nioghalvfjerdsfjorden Glacier, Northeast Greenland. Journal of Geophysical Research Oceans 122(5), 4004-4020 doi: 10.1002/2016)C012462.

Schaffer J and 5 others (2020) Bathymetry constrains ocean heat supply to Greenland's largest glacier tongue. Nature Geoscience 13, 227-231. doi: 10.1038/s41561- 019-0529-x

Schröder L, Neckel N, Zindler R and Humbert A (2020) Perennial supraglacial lakes in Northeast Greenland observed by Polarimetric SAR. Remote Sensing 12(17), 2798. doi: 10.3390/rs12172798

Seroussi H and 6 others (2011) Ice flux divergence anomalies on 79North glacier, Greenland. Geophysical Research Letters 38(9), L09501 doi: 10.1029/ 2011 GL047338.

Smeets CJPP and van den Broeke MR (2008) Temporal and spatial variation of the aerodynamic roughness length in the ablation zone of the Greenland Ice Sheet. Boundary Layer Meteorology 128, 315-338. doi: 1.1007/ s10546-008-9291-0

Solgaard A and Kusk A (2019) Programme for monitoring of the Greenland ice sheet (PROMICE): Greenland ice velocity. Geological survey of Denmark and Greenland (GEUS) doi: 10.22008/promice/data/sentinellicevelocity/greenlandicesheet/v1.0.0

Thomsen HH and 6 others (1997) The Nioghalvfjerdsfjorden glacier project, North-East Greenland: a study of ice sheet response to climatic change. Geology of Greenland Survey Bulletin 176, 95-103.

Turton JV, Mölg T and Collier E (2019b) NEGIS_WRF model output, Open Science Framework Repository (doi: 10.17605/OSF.IO/53E6Z ) In URL: https://osf.io/53e6z/ (last accessed on 09 May 2019).

Turton JV, Mölg T and Collier E (2020) High-resolution (1 km) polar WRF output for $79^{\circ} \mathrm{N}$ glacier and the Northeast of Greenland from 2014-2018. Earth System Science Data 12(2), 1191-1202. doi: 10.5194/essd12-1191-2020

Turton JV, Mölg T and van As D (2019a) Atmospheric processes and climatological characteristics of the $79 \mathrm{~N}$ glacier (Northeast Greenland). Monthly Weather Review 147(4), 1375-1394. doi: 10.1175/MWR- D-18-0366.1

van As D (2011) Warming, glacier melt and surface energy budget from weather station observations in the Melville Bay region of northwest Greenland. Journal of Glaciology 57(202), 208-220. doi: 10.3089/ 002214311796405898

van de Wal RSW and Oerlemans J (1994) An energy balance model for the Greenland ice sheet. Global and Planetary Change 9(1-2), 115-131. doi: 10. 10160921-8181(94)90011-6

Vionnet V and 7 others (2012) The detailed snowpack scheme Crocus and its implementation in SURFEX v7.2. Geoscientific Model Development 5(3), 773-791 doi: 10.1029/2010JD015013.

Zeising O, Neckel N, Steinhage D, Scheinert M and Humbert A (2020) Stake surface ablation/accumulation measurements at $79^{\circ} \mathrm{N}$ Glacier between 2017 and 2018 doi:10.1594/PANGAEA.922131 In URL: https://doi.pangaea.de/ 10.1594/PANGAEA.922131 (last accessed on 20 September 2020). 


\section{Appendix A: Ablation stake locations}

See Table 4 .

Table 4. GPS locations of the ablations stakes and the measurement results

\begin{tabular}{|c|c|c|c|c|c|c|c|}
\hline \multirow[b]{2}{*}{ Stake ID } & \multirow[b]{2}{*}{ Longitude ${ }^{\circ} \mathrm{N}$} & \multirow[b]{2}{*}{ Latitude ${ }^{\circ} \mathrm{E}$} & \multirow[b]{2}{*}{ Altitude m } & \multirow[b]{2}{*}{ Difference m } & \multirow[b]{2}{*}{$\mathrm{SD} \mathrm{m}$} & \multicolumn{2}{|c|}{$\begin{array}{l}\text { Number of } \\
\text { measurements }\end{array}$} \\
\hline & & & & & & 2017 & 2018 \\
\hline pRES_g1_p03 & 79.6657 & -20.2634 & 13.7 & -0.50 & 0.11 & 3 & 3 \\
\hline pRES_g1_p04 & 79.6533 & -19.6843 & 8.4 & -0.65 & 0.04 & 3 & 3 \\
\hline pRES_g1_p05 & 79.5680 & -19.6559 & 3.9 & -0.72 & 0.03 & 3 & 3 \\
\hline pRES_g1_p06 & 79.5156 & -20.0776 & 4.4 & -0.67 & 0.09 & 3 & 3 \\
\hline pRES_g1_p07 & 79.5308 & -20.5678 & 13.9 & -0.53 & 0.01 & 3 & 3 \\
\hline pRES_g1_p12 & 79.3946 & -21.7414 & 18.9 & -0.89 & 0.06 & 3 & 3 \\
\hline pRES_g1_p13 & 79.4270 & -21.8272 & 42.3 & -0.76 & 0.03 & 3 & 3 \\
\hline pRES_g1_p14 & 79.4522 & -21.9144 & 18.7 & -0.82 & 0.07 & 3 & 3 \\
\hline pRES_g1_NIO1 & 79.4702 & -21.8097 & 15.5 & -0.70 & $\mathrm{NaN}$ & 1 & 1 \\
\hline pRES_g2_p01 & 79.3917 & -22.6721 & 40.1 & -1.12 & 0.44 & 3 & 3 \\
\hline pRES_g2_p02 & 79.4016 & -22.6104 & 26.9 & -1.35 & 0.25 & 3 & 3 \\
\hline pRES_g2_p03 & 79.4178 & -22.4983 & 27.2 & -1.22 & 0.23 & 3 & 3 \\
\hline pRES_g2_p04 & 79.4073 & -22.4875 & 34.3 & -1.02 & 0.03 & 3 & 3 \\
\hline pRES_g2_p05 & 79.3910 & -22.5272 & 42.3 & -1.53 & 0.07 & 3 & 3 \\
\hline pRES_g2_p06 & 79.3924 & -22.4756 & 29.3 & -1.27 & 0.16 & 3 & 3 \\
\hline pRES_g2_p07 & 79.3799 & -22.5284 & 43.3 & -1.25 & 0.12 & 3 & 3 \\
\hline pRES_g2_p08 & 79.3510 & -22.4877 & 48.6 & -1.09 & 0.04 & 3 & 3 \\
\hline pRES_g2_p09 & 79.3744 & -22.3017 & 42.7 & -0.78 & 0.10 & 3 & 3 \\
\hline pRES_g2_p10 & 79.2908 & -22.4396 & 36.1 & -0.80 & 0.04 & 3 & 3 \\
\hline pRES_g2_p11 & 79.3165 & -22.2900 & 36.3 & -0.64 & 0.02 & 3 & 3 \\
\hline pRES_g2_p12 & 79.3304 & -22.2003 & 21.4 & -0.71 & 0.07 & 3 & 3 \\
\hline pRES_g2_p13 & 79.3574 & -22.0178 & 22.3 & -0.67 & 0.07 & 3 & 3 \\
\hline pRES_g2_p15 & 79.4167 & -22.0029 & 40.2 & -0.82 & 0.06 & 3 & 3 \\
\hline pRES_g3_p01 & 79.4578 & -22.4039 & 18.7 & -1.72 & 0.39 & 3 & 3 \\
\hline pRES_g3_p02 & 79.4338 & -22.4675 & 23.7 & -1.37 & 0.10 & 3 & 3 \\
\hline pRES_g3_p03 & 79.4197 & -22.5702 & 22.3 & -1.58 & 0.06 & 3 & 3 \\
\hline pRES_g3_p04 & 79.4188 & -22.4265 & 34.6 & -1.11 & 0.07 & 3 & 3 \\
\hline pRES_g3_p05 & 79.4214 & -22.4300 & 23.8 & -1.09 & 0.15 & 3 & 3 \\
\hline pRES_g3_p06 & 79.4071 & -22.5662 & 25.2 & -1.37 & 0.15 & 3 & 3 \\
\hline pRES_g3_p07 & 79.4024 & -22.5961 & 22.9 & -0.86 & 0.08 & 3 & 3 \\
\hline pRES_g3_p08 & 79.4014 & -22.3581 & 27.1 & -0.79 & 0.15 & 3 & 3 \\
\hline pRES_g3_p09 & 79.3913 & -22.3137 & 23.1 & -0.76 & 0.05 & 3 & 3 \\
\hline pRES_g3_p10 & 79.3813 & -22.3809 & 25.5 & -0.96 & 0.20 & 3 & 3 \\
\hline pRES_g3_p11 & 79.3744 & -22.4433 & 32.9 & -0.76 & 0.30 & 3 & 3 \\
\hline pRES_g3_p12 & 79.3644 & -22.5175 & 37.1 & -1.15 & 0.08 & 3 & 3 \\
\hline pRES_g3_p13 & 79.3561 & -22.2635 & 42.5 & -0.67 & 0.01 & 2 & 3 \\
\hline pRES_g3_p14 & 79.3516 & -22.2506 & 34.2 & -0.98 & 0.18 & 3 & 3 \\
\hline pRES_g3_p15 & 79.3476 & -22.2430 & 28.5 & -0.59 & 0.06 & 3 & 3 \\
\hline pRES_g3_p16 & 79.2940 & -22.2488 & 47.1 & -0.81 & 0.07 & 3 & 3 \\
\hline pRES_g3_p17 & 79.3119 & -22.3708 & 27.0 & -0.67 & 0.03 & 3 & 3 \\
\hline pRES_g4_p01 & 79.3776 & -22.6102 & 59.9 & -1.51 & 0.04 & 2 & 2 \\
\hline pRES_g4_p02 & 79.3195 & -22.5170 & 48.0 & -1.64 & 0.29 & 2 & 2 \\
\hline pRES_g4_p03 & 79.3786 & -22.7844 & 83.2 & -1.24 & 0.53 & 2 & 2 \\
\hline GPS01_1718 & 79.4148 & -22.5212 & 28.3 & -1.16 & 0.13 & 4 & 3 \\
\hline GPS02_1718 & 79.3844 & -23.7274 & 76.3 & -1.03 & 0.02 & 2 & 2 \\
\hline GPS05_1718 & 79.1439 & -24.3951 & 831.3 & 1.09 & 0.06 & 4 & 3 \\
\hline GPS06_1718 & 79.1930 & -23.7660 & 715.5 & 0.76 & 0.10 & 4 & 4 \\
\hline GPS07_1718 & 79.2880 & -23.1208 & 349.4 & -0.98 & 0.07 & 4 & 3 \\
\hline GPS08_1718 & 79.3506 & -22.6553 & 74.2 & -0.72 & 0.24 & 4 & 4 \\
\hline pRES_IN02 & 79.2858 & -23.8484 & 728.7 & 0.73 & 0.14 & 2 & 2 \\
\hline
\end{tabular}

The altitude is measured with the GPS relative to an ellipsoid. Deviations can occur due to GPC inaccuracies ( 10 m) and tidal movement of the glacier tongue ( $3 \mathrm{~m})$. 'Difference' is the difference of the snow height in July 2018 relative to July 2017 observations. At each site up to four measurements were takes. The exact number of measurements at each site are listed. The SD is the standard deviations of all measurements taken from one site (Zeising, and others 2020). 


\section{Appendix B: Manual optimization scheme}

See Tables 5 and 6.

Table 5. List of parameterization options available in v1.3 COSIPY (Sauter and others, 2020)

\begin{tabular}{lll}
\hline Parameterization & Parameterization scheme & References \\
\hline Stability correction & $\begin{array}{l}\text { 'Bulk Richardson Number' ('Ri') } \\
\text { 'Monin-Obukhov similarity theory ('Mo') }\end{array}$ & Braithwaite (1995) \\
Densification method & $\begin{array}{l}\text { 'Boone' } \\
\text { 'Vionnet' }\end{array}$ & Vionnet and others (2012); Essery and others (2013)
\end{tabular}

Table 6. List of key parameters and the range of values tested in model optimization

\begin{tabular}{lll}
\hline Parameter & $\begin{array}{l}\text { Value range } \\
\text { (min-max) }\end{array}$ & \\
\hline Albedo fresh snow & $0.8-0.90$ & van de Wal and Oerlemans (1994); Oerlemans and Knap (1998) \\
Albedo firn & $0.4-0.8$ & Bøggild and others (2010); exceeding based on AWS observations \\
Albedo ice & $0.3-0.6$ & van de Wal and Oerlemans (1994); Bøggild and others (2010) \\
Albedo time scaling factor & $1-21 \mathrm{~d}$ & Default value (21 d); Helsen and others (2017) \\
Albedo depth scaling factor & $1-30 \mathrm{~cm}$ & Oerlemans and Knap (1998); AWS-measured snow height at KPC-L (0.33 cm) \\
Roughness length fresh snow & $0.24-0.5 \mathrm{~mm}$ & Cullen and others (2014); Fausto and others (2016) \\
Roughness length firn & $0.7-2.7 \mathrm{~mm}$ & Mölg and others (2012) \\
Roughness length ice & $2.4-5 \mathrm{~mm}$ & Smeets and Van den Broeke (2008); Fausto and others (2016) \\
Surface emissivity & $0.97(\mathrm{default})-1$ & Cullen and others (2014); Noël and others (2018) \\
Density threshold to firn & $400-500 \mathrm{~kg} \mathrm{~m}^{-3}$ & Cullen and others (2014) \\
\hline
\end{tabular}

\section{Appendix C: Local climate and radiative conditions}

See Figures 9 and 10.
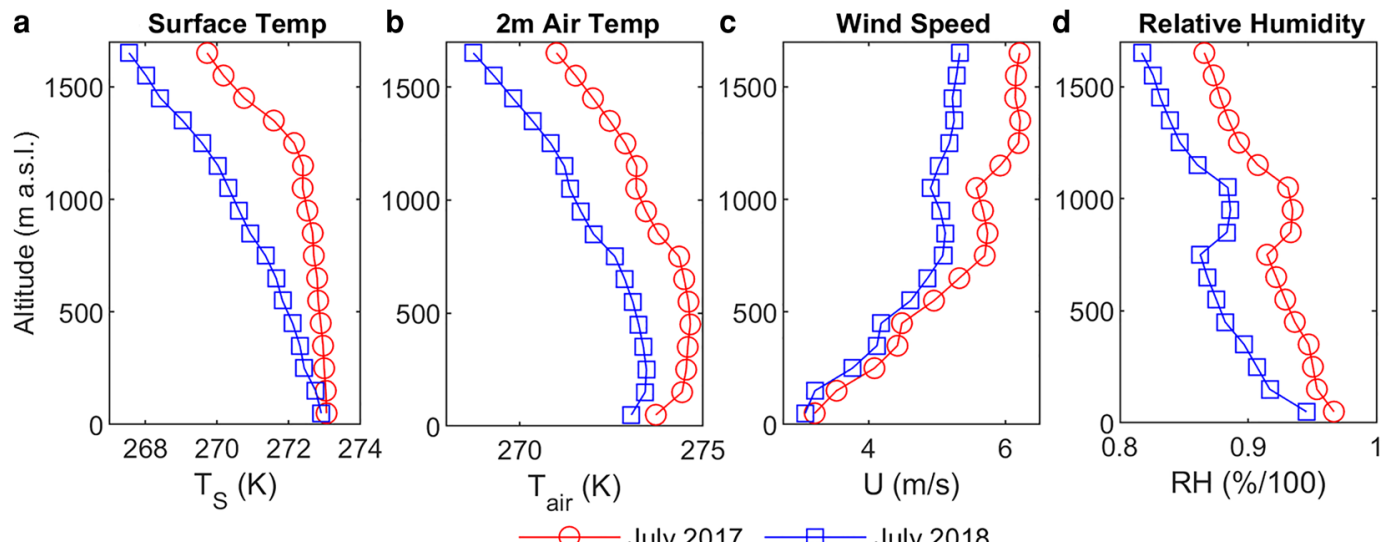

Fig. 9. Average vertical profiles (altitude bands of $50 \mathrm{~m}$ ) for the surface temperature from COSIPY-WRF (a) and the mean climate conditions $-2 \mathrm{~m}$ air-temperature (b), $2 \mathrm{~m}$ wind speed (c) and relative humidity - from the PWRF output at the 79N region in July 2017 and July 2018. The surface temperature.
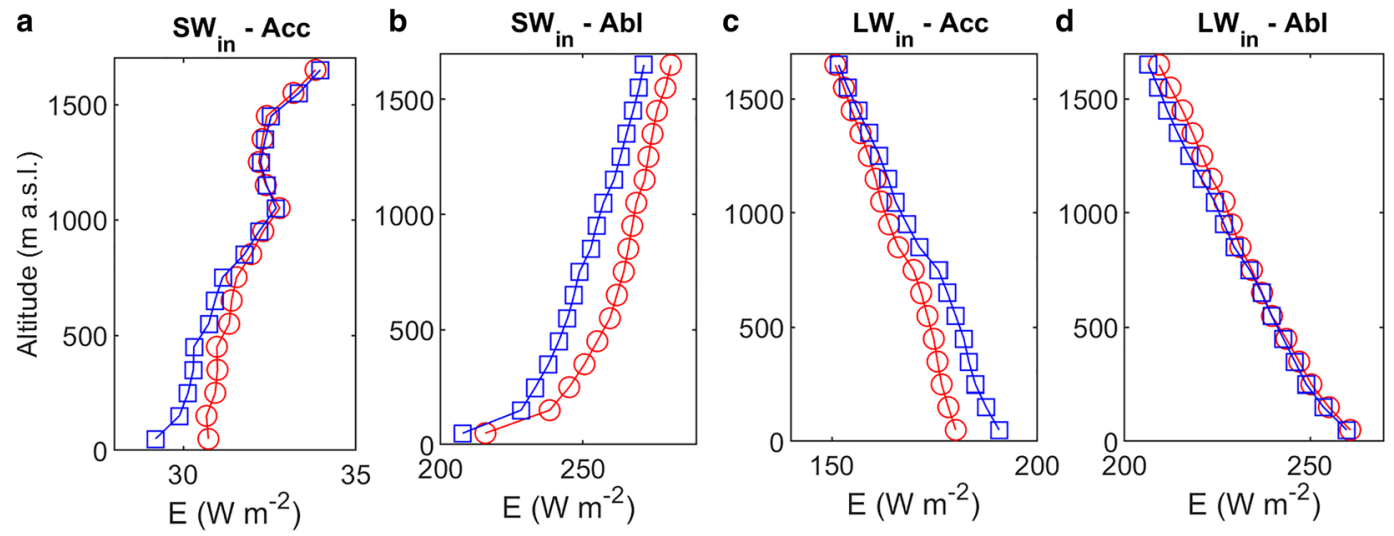

Fig. 10. Average vertical profile (altitude bands of $50 \mathrm{~m}$ ) for the components of incoming shortwave radiation, $\mathrm{SW}_{\text {in }}\left(\mathrm{a}\right.$ and $\mathrm{b}$ ) and incoming longwave radiation, $\mathrm{LW}_{\text {in }}$ ( $c$ and f) from COSIPY-WRF with energy flux density on the $x$-axis. The data are averaged over the accumulation periods (October 2016 to April 2017 , and October 2017 to April 2018) and over the ablation periods (May to September 2017 and May to September 2018). 